\title{
A simple rule to determine which insolation cycles lead to interglacials
}

\author{
P. C. Tzedakis ${ }^{1}$, M. Crucifix ${ }^{2}$, T. Mitsui ${ }^{2} \&$ E. W. Wolff ${ }^{3}$ \\ ${ }^{1}$ Environmental Change Research Centre, Department of Geography, University College London, London, UK. \\ ${ }^{2}$ Université catholique de Louvain, Earth and Life Institute, Georges Lemaitre Centre for Earth and Climate \\ Research, Louvain-la-Neuve, Belgium. \\ ${ }^{3}$ Department of Earth Sciences, University of Cambridge, Cambridge, UK.
}

The pacing of glacial-interglacial cycles during the Quaternary period (the past 2.6 million years) is attributed to astronomically driven changes in high-latitude insolation. However, it has not been clear how astronomical forcing translates into the observed sequence of interglacials. Here we show that before one million years ago interglacials occurred when the energy related to summer insolation exceeded a simple threshold, about every 41,000 years. Over the past one million years, fewer of these insolation peaks resulted in deglaciation (that is, more insolation peaks were 'skipped, implying that the energy threshold for deglaciation had risen, which lead to longer glacials. However, as a glacial lengthens, the energy needed for deglaciation decreases. A statistical model that combines these observations correctly predicts every complete deglaciation of the past million years and shows that the sequence of interglacials that has occurred is one of a small set of possibilities. The model accounts for the dominance of obliquity-paced glacial-interglacial cycles early in the Quaternary and for the change in their frequency about one million years ago. We propose that the appearance of larger ice sheets over the past million years was a consequence of an increase in the deglaciation threshold and in the number of skipped insolation peaks.

The Milanković astronomical theory of ice ages ${ }^{1}$ posits that quasi-periodic expansions and contractions of Northern Hemisphere ice sheets are driven by variations in Earth's orbital geometry and axial inclination that influence the amount of summer insolation received at northern high latitudes. Astronomical periodicities of obliquity (41,000-year (41-kyr) cycles) and precession (23- and 19-kyr cycles) were found to be embedded in records of changing ice volume and climate ${ }^{2}$; however, in addition to these cycles, climate variance in the Middle and Late Pleistocene was dominated by a 100-kyr cycle ${ }^{2}$, which was not predicted by the original theory. The development of improved chronologies ${ }^{3}$ and advances in demarcating interglacial boundaries ${ }^{4}$ have shown that the onset of interglacials over the past 600 kyr occurred near the 
maximum in boreal summer insolation, with perihelion (when Earth is nearest to the Sun) at the northern summer solstice. Mean daily insolation on 21 June at $65^{\circ} \mathrm{N}$ is often used as a predictor of glacial changes, because it represents maximum values at a sensitive time of the year at a critical latitude for ice-sheets. However, the data in Fig. 1 reveal that not all insolation maxima led to interglacials: some prominent insolation peaks are associated with incomplete deglaciations - that is, interstadials (for example, Marine Isotope sub-Stages (MIS) 6e and 9a) — and some prominent interglacials are associated with moderate insolation maxima, most notably MIS 11c (ref. 5). It is, in fact, difficult to decide which insolation maxima would lead to interglacials by using only this insolation curve. An additional complication is that deglaciations occurred approximately every $41 \mathrm{kyr}$ (the so-called '41-kyr world') up until about one million years before present (1 Myr BP), but have been less frequent since then (the so-called '100-kyr world', but see below). Therefore, any comprehensive explanation of how astronomical forcing translates into the sequence of Quaternary ice ages needs to account for the occurrence of interglacials at different frequencies.

Several numerical models ${ }^{6-16}$ have reproduced the pattern, and in some cases much of the timing, of glacial-interglacial cycles over part or all of the Quaternary. Although each of these has pointed at some of the ingredients involved in a comprehensive explanation, some include large numbers of tunable parameters, none is fully successful over the past million years, and few offer a consistent and simple rule that accounts for the whole Quaternary sequence. Here we ask whether the onset of interglacials over the course of the Quaternary can be predicted from simple combinations of astronomical parameters (that is, without any knowledge of atmospheric $\mathrm{CO}_{2}$ concentration, dust or other climate data). We determine the parameters of such a model in a statistical way, which allows us to discuss whether a simple model can successfully accommodate the observed sequence and to assess how tightly the succession of ice ages is controlled by the astronomical forcing.

\section{Defining interglacials}

To predict when deglaciations occur, we first need to define the population of interglacials. The fundamental property that underlies the concept of an interglacial is high sea-level-a measure of integrated global climate effects that lead to the loss of continental ice ${ }^{4}$. The marine oxygen isotope stratigraphy is divided into glacial and interglacial stages, on the basis that variations in the oxygen isotope ratio $\left(\delta^{18} \mathrm{O}\right)$ in benthic foraminifera primarily reflect changes in continental ice ${ }^{17,18}$. However, there has never been a systematic attempt to 
distinguish complete deglaciations (interglacials) from incomplete deglaciations (interstadials) over the past $2.6 \mathrm{Myr}$. A recent review ${ }^{19}$ of the past $800 \mathrm{kyr}$ proposed that an objective definition of an interglacial is the absence of substantial Northern Hemisphere ice outside Greenland. This equates to a criterion that separates interglacials from interstadials on the basis of residual Northern Hemisphere ice. Because sufficiently precise sea-level records are not available for the past $2.6 \mathrm{Myr}$, we have adapted the auxiliary definition ${ }^{19}$ that used the LR04 benthic $\delta^{18} \mathrm{O}$ stack $^{20}$. The objective set of criteria is described in Methods. A period is an interglacial if its isotopic value is below a threshold. Two isotopic minima (for example, MIS 15e and 15a) are separate interglacials if there is a local maximum above a second threshold between them; otherwise, the second isotopic minimum forms a continued interglacial (for example, MIS 7a is a continuation of MIS 7c), without a glacial termination or interglacial onset (Extended Data Figs 1-3 and Supplementary Table 1). An important aspect of this definition is the occurrence of more than one interglacial within an isotope stage - a divergence from traditional assumptions about the temporal spacing of interglacials. As a result, interglacials of the past $800 \mathrm{kyr}$ (Fig. 1) do not occur every $100 \mathrm{kyr}$ and are not always preceded by one of the traditionally numbered glacial terminations defined over this interval $^{19}$. Any attempt to predict the onset of interglacials needs to account for this irregular temporal spacing.

\section{Choosing an insolation metric}

Variations in summer solstice insolation are driven mainly by precessional changes. When perihelion is in June, northern high latitudes receive more insolation per day; but, according to Kepler's second law, summers are shorter, which reduces the length of the ice-ablation season $^{21}$. Independently of precession, an increase in obliquity acts positively on the total amount of insolation received over summer ${ }^{1,21}$, and this effect is largest at high latitudes. To account for the combined effects of precession and obliquity, Milankovic ${ }^{1}$ used 'caloric summer half-year insolation', which represents the amount of energy integrated over the caloric summer half of the year, defined such that any day of the summer half receives more insolation than any day of the winter half. Near $65^{\circ} \mathrm{N}$, the variance of this measure has almost equal contributions from precession and obliquity. Climate model simulations ${ }^{22}$ show that variations in positive degree-days (the sum of temperatures over days for which the temperature is positive at northern high latitudes are approximately equally sensitive to precession and obliquity, justifying the use of the caloric summer half-year insolation as the measure most relevant to ice-sheet loss. This metric has a pattern that is very similar to that of 
the total summer energy at $65^{\circ} \mathrm{N}$ integrated over all days for which insolation exceeds $350 \mathrm{~W} \mathrm{~m}^{-2}$ (ref. 12).

\section{Deriving a simple scheme}

Figure 2 shows the $65^{\circ} \mathrm{N}$ caloric summer insolation curve in relation to the LR04 benthic stack. The red, black and light blue symbols indicate the caloric summer insolation maxima that are nearest to the onsets of interglacials, continued interglacials and interstadials, respectively. The onset of every interglacial occurs during intervals of above-average obliquity ( $>23.3^{\circ}$; grey shading in Fig. 2 ), and from 2.6 Myr BP to 1 Myr BP most interglacials are spaced about every $41 \mathrm{kyr}$. This result reflects the fact that the values of caloric summer insolation above a threshold are much more likely to occur when obliquity is high, suggesting that the 41-kyr glacial-interglacial cycle arises, at least in part, simply because every second insolation peak is boosted by high obliquity. Reduced ice accumulation at times of higher obliquity may also have contributed to a $41-\mathrm{kyr}$ spacing of interglacials ${ }^{23}$. However, not every interval of above-average obliquity is associated with an interglacial, especially during the past $1 \mathrm{Myr}$, when 12 out of 25 obliquity peaks were skipped.

The data in Fig. 3, which displays the peak caloric summer insolation values for interglacials, continued interglacials and interstadials over the past $2.6 \mathrm{Myr}$, show that there is no single insolation threshold separating interglacials from interstadials throughout the Quaternary. However, of the 67 caloric summer insolation peaks before 1 Myr BP, 36 associated with interglacials (and 7 with continued interglacials) are above approximately $5.945 \mathrm{GJ} \mathrm{m}^{-2}$, and 21 associated with interstadials are below that value. Demarcation based on this insolation threshold produces two false negatives (MIS 63 and 71) and one false positive (2,212 kyr BP). However, when we consider alternative and well-resolved benthic isotope records (Methods and Supplementary Table 1), MIS 71 is an uncertain interglacial and 2,212 kyr BP an uncertain interstadial, leaving just one confirmed false negative (MIS 63) out of 67 insolation peaks. Timescale uncertainties might have led to MIS 63 being assigned to the wrong insolation peak $(1,781 \mathrm{kyr} \text { BP instead of } 1,761 \mathrm{kyr} \mathrm{BP})^{24}$, in which case it would change to a correct classification in our scheme.

After 1 Myr BP, the insolation threshold for deglaciation appears to be higher (no interglacials below $5.979 \mathrm{GJ} \mathrm{m}^{-2}$ ). However, it is impossible to define an interglacial space without also including several false positives (MIS 5a, 6e, 9a, 11a, 13c and 23, and 999 kyr BP). These interstadials occurred early in glacial periods and were not preceded by 
substantial ice accumulations, in contrast to major deglaciations, which usually follow the largest accumulations of ice $\mathrm{e}^{7,25,26}$. This difference suggests that a complete rule needs to incorporate glacial history.

We therefore introduce the additional component that the threshold for a complete deglaciation decreases with the amount of time that has elapsed since the onset of the previous interglacial. This is the simplest way to incorporate the idea that, over time, the glacial system accumulates instability ${ }^{27}$ that makes ice sheets more sensitive to insolation increases. This instability can be due to any of the following negative feedbacks on ice growth: (i) mechanical instabilities of the ice-bedrock system, enhanced calving and exposure to lower-latitude insolation as ice sheets grow $^{28-30}$; (ii) a decrease in ice-sheet albedo and an increase in ablation as a result of higher rates of dust deposition as ice sheets expand ${ }^{13}$; and (iii) releases of deep-ocean $\mathrm{CO}_{2}$ as a function of extension of the Antarctic ice sheet over continental shelves ${ }^{9,31}$.

We estimate the time since the onset of the previous interglacial as the interval from the caloric summer insolation peak nearest to the onset of an interglacial to an ensuing insolation peak. This elapsed time is determined for every local insolation maximum between the onsets of two successive interglacials, on the assumption that each insolation peak could potentially have led to a complete deglaciation (Extended Data Fig. 4). A more precise definition might have involved measuring time from glacial inception, but here we make the approximation that instability begins to accumulate from the insolation maximum so that we retain a simple model that uses only astronomical forcing and elapsed time as input.

We then plot peak caloric summer insolation and associated elapsed times for the interval 0-1 Myr BP (Fig. 4). The diagonal line separates insolation peaks associated with interglacial onsets from peaks associated with interstadials (and one continued interglacial). The $y$ intercept $\left(E_{0}, 6.14 \pm 0.01 \mathrm{GJ} \mathrm{m}^{-2}\right.$; quoted uncertainties here and elsewhere are the inner 50th percentile of the credible interval) of such a line represents the insolation threshold for deglaciation when there is zero elapsed time. The decreasing slope of the line $\left(0.0021 \pm 0.0001 \mathrm{GJ} \mathrm{m}^{-2} \mathrm{kyr}^{-1}\right)$ represents the discount rate $b$ of the insolation required for deglaciation. Combined with the time since the previous deglaciation $\Delta t$ (in kyr), the discount rate provides a measure of accumulated instability that lowers the insolation threshold required for deglaciation. For each caloric summer insolation peak, $I_{\text {peak }}\left(\mathrm{GJ} \mathrm{m}^{-2}\right)$, the effective energy $\left.E\left(I_{\text {peak }}, \Delta t\right) \mathrm{GJ} \mathrm{m}^{-2}\right)$ is here defined as 
$E\left(I_{\text {peak }}, \Delta t\right)=I_{\text {peak }}+b \Delta t$

A complete deglaciation occurs when the effective energy $E\left(I_{\text {peak }}, \Delta t\right)$ exceeds the deglaciation threshold $E_{0}$.

Figure 5 shows the effective energy for each peak in caloric summer insolation as a function of age for the past 2.6 Myr. Compared to the diffuse pattern in the interval after 1 Myr BP in Fig. 3, in which a discount rate was not included, what emerges is an orderly arrangement of interglacial onsets above the $E_{0}$ threshold after $1 \mathrm{Myr}$ BP. This higher deglaciation threshold led to an increase in the frequency of skipped caloric summer insolation peaks. For example, MIS 5a, 6e, 9a, 11a, 13c and 23, and 999 kyr BP, which are characterized by intermediate caloric summer insolation peaks and short times since the previous deglaciation (Fig. 4), were skipped, because the effective energy was not sufficient to cross the deglaciation threshold. On the other hand, the strong insolation peaks of MIS 7c and $15 \mathrm{a}$ were able to cross the deglaciation threshold despite short elapsed times, and MIS 11c, 13a and 19c with weaker insolation peaks benefitted from long elapsed times. MIS 3, despite an 77-kyr elapsed time, narrowly failed to cross the threshold because of its moderate insolation peak, a function of the modulation of precession by a minimum in eccentricity at that time. Relatively weak insolation peaks at $505 \mathrm{kyr}$ BP, $712 \mathrm{kyr}$ BP and 885 kyr BP, which occurred when obliquity was below average, did not cross the deglaciation threshold despite long elapsed times. Before 1 Myr BP, the model with a discount rate performs about the same as the one without. There are no longer any false positives, but two false negatives (MIS 59 and 63, the latter with some uncertainty over the correct insolation peak attribution, as noted earlier). Elapsed times are generally short, but the data for before 1 Myr BP (Extended Data Fig. 5) are consistent with the use of the same discount rate as in the later period.

When using summer solstice mean daily insolation at $65^{\circ} \mathrm{N}$ instead of caloric summer insolation, our model performs slightly worse (one false negative and one false positive) for the past 1 Myr, and markedly worse for earlier times (Methods, Extended Data Figs 6-9 and Supplementary Table 2). Unsurprisingly, summer solstice insolation, with $80 \%$ of its variance in the precession band, emerges as a weaker predictor of glacial-interglacial cycles of the 41kyr world. 


\section{Predictability}

We now investigate whether the sequence of glacial-interglacial cycles is robustly determined. The data in Fig. 4 suggest that over the past 1 Myr the intercept and slope of the line separating complete and incomplete deglaciations are well constrained by observations. However, a small level of stochasticity in ice volume, ice albedo or $\mathrm{CO}_{2}$ effects, small differences in other forcings (solar or volcanic), and internal variability in the climate system could change the outcome for those insolation peaks near the threshold. In addition, elapsed time is an approximation for a more complex function of the insolation history since the previous interglacial, and this is another source of uncertainty in our model.

We calibrate a statistical model based on logistic regression to estimate the insolation threshold and discount rate (Methods) and then sample possible histories of interglacial onsets throughout the past $1 \mathrm{Myr}$ (Fig. 6). Among the 25,000 Monte Carlo sample of potential histories simulated with this approach, the history that was actually observed is generated with highest frequency. The most frequent alternatives are an absence of deglaciation at MIS 7c (it then occurs at MIS 6e), deglaciation at MIS 11a instead of MIS 11c, and deglaciation at MIS 3 with MIS 1 becoming an interstadial. Our analysis suggests that over the past 1 Myr small climate differences and effects not accounted for by our model could have altered the sequence of interglacials, but the extent of modification is limited by cycles with strong caloric summer insolation, anchoring the occurrence of some interglacials (for example, MIS 25, 9e and 5e). We can therefore answer the question of whether, starting from 2.6 Myr BP with only astronomical forcing prescribed, we would inevitably find ourselves in our present interglacial climate: irrespective of whether the same sequence of earlier interglacials is repeated or not, it is the extent of the MIS 3 deglaciation that decides the fate of MIS 1.

\section{The rise in the deglaciation threshold}

Unlike Fig. 3, in which the insolation threshold of about $5.945 \mathrm{GJ} \mathrm{m}^{-2}$ separates interglacials and continued interglacials from interstadials before 1 Myr BP, the threshold line in Fig. 5 separates complete from incomplete deglaciations. Continued interglacials, which by definition are not associated with a deglaciation, are therefore below the threshold line and do not reset the clock in terms of calculating elapsed times. The distribution of interglacials versus interstadials and continued interglacials in Fig. 5 indicates the presence of a change in threshold before 1 Myr BP, treated here as a linear ramp. 
We therefore generalize the logistic model to include the ramp function. Our classification of whether an insolation peak is coded red, light blue or black is assumed to be certain for all events after 1 Myr BP. Before that, however, the classification of events is more subject to uncertainties (chronology, sea-level estimates, divergence between records and less clear separation into interglacial and interstadial populations). We encode this uncertainty in the likelihood function, by considering that there is a $10 \%$ probability of misclassification before 1 Myr BP. With these assumptions, the ramp in Fig. 5 can be modelled as a gradual shift in the deglaciation threshold from $6.02 \mathrm{GJ} \mathrm{m}^{-2}$ to $6.14 \mathrm{GJ} \mathrm{m}^{-2}$ between 1.55 Myr BP and 0.61 Myr BP (Methods and Extended Data Fig. 10).

Several independent lines of evidence point to a transition in the mode of glacialinterglacial cycles, starting from MIS 52 (about $1.54 \mathrm{Myr} \mathrm{BP})^{32}$. Glacial ice volume increased, North Atlantic sea-surface temperatures decreased and ice-rafted detritus increased ${ }^{32-34}$, while vertical carbon isotope gradients between the intermediate and deep Atlantic increased ${ }^{35,36}$. A further change occurred at the MIS 38/37 transition, with the appearance of more abrupt glacial terminations, intensification of cooling and increased Southern Ocean dust and iron flux; this change signals the onset of the so-called Middle Pleistocene Transition (1.25$0.65 \mathrm{Myr} \mathrm{BP})$ towards lower-frequency, higher-amplitude glacial cycles ${ }^{32,37-44}$. The interval MIS 25-22 contains a skipped deglaciation at MIS 23 and increasing ice volume, culminating in the first major glaciation at about $0.9 \mathrm{Myr}$ BP according to sea-level reconstructions ${ }^{45}$ and glacial geologic evidence ${ }^{44,46}$.

Secular decline in $\mathrm{CO}_{2}$ concentrations ${ }^{8,25,35,42,47}$, progressive regolith erosion ${ }^{41}$, topographic changes by glacial erosion and strengthening of the Nordic Heat Pump ${ }^{48}$, and sea-ice switching mechanisms ${ }^{49}$, among others, have been invoked to account for the observed long-term changes in the strength and frequency of Northern Hemisphere glaciation. Whatever the underlying causes, we suggest that a climate transition and a gradual rise in the deglaciation threshold starting about 1.55 Myr BP led to an increase in the frequency of skipped caloric summer insolation peaks of above-average obliquity since $1 \mathrm{Myr}$ BP. The emergence of longer glacials then allowed the accumulation of larger and increasingly unstable ice sheets.

\section{Conclusions}

Whereas previous works have considered only traditional glacial terminations (thereby ignoring additional deglaciations) or assessed the performance of a model by comparing to a 
target benthic isotope curve without separating complete or incomplete deglaciations, here we have developed a robust taxonomy of interglacials, continued interglacials and interstadials for the entire Quaternary. We constructed the simplest possible model to describe and predict whether a particular insolation peak led to the onset of an interglacial throughout the past 2.6 Myr on the basis of a single insolation measure (caloric summer half-year insolation) and the time since the previous deglaciation. The model correctly predicts every complete deglaciation of the past million years and shows that the succession of interglacial onsets that has occurred is one of a small set of possibilities.

Future work should aim to add more mechanistic detail into our rules by narrowing the causes of the Early Pleistocene rise in the deglaciation threshold and quantifying how elapsed time contributes to glacial instability through glaciological or carbon-cycle processes. Such studies would be a further step towards a process-based understanding of glacialinterglacial cycles and the development of an extended astronomical theory of ice ages. Received 19 February 2016; accepted 9 January 2017.

1. Milanković, M. Kanon der Erdbestrahlung und seine Anwendung auf das Eiszeitenproblem (Royal Serbian Academy, 1941).

2. Hays, J. D., Imbrie, J. \& Shackleton, N. J. Variations in the Earth's orbit: pacemaker of the ice ages. Science 194, 1121-1132 (1976).

3. Cheng, H. et al. The Asian monsoon over the past 640,000 years and ice age terminations. Nature 534, 640-646 (2016).

4. Tzedakis, P. C. et al. Can we predict the duration of an interglacial? Clim. Past $\mathbf{8}$, 1473-1485 (2012).

5. Imbrie, J. et al. On the structure and origin of major glaciation cycles. 2. The 100,000-year cycle. Paleoceanography 8, 699-735 (1993).

6. Saltzman, B. \& Maasch, K. A. A first-order global model of late Cenozoic climate. Trans. R. Soc. Edinb. Earth Sci. 81, 315-325 (1990).

7. Paillard, D. The timing of Pleistocene glaciations from a simple multiple-state climate model. Nature 391, 378-381 (1998).

8. Berger, A., Li, X. S. \& Loutre, M. F. Modelling Northern Hemisphere ice-volume over the last 3 Ma. Quat. Sci. Rev. 18, 1-11 (1999). 
9. Paillard, D. \& Parrenin, F. The Antarctic ice-sheet and the triggering of deglaciations. Earth Planet. Sci. Lett. 227, 263-271 (2004).

10. Tziperman, E., Raymo, M. E., Huybers, P. \& Wunsch, C. Consequences of pacing the Pleistocene $100 \mathrm{kyr}$ ice ages by nonlinear phase locking to Milankovitch forcing. Paleoceanography 21, PA4206 (2006).

11. Huybers, P. Glacial variability over the last two million years: an extended depthderived age model, continuous obliquity pacing, and the Pleistocene progression. Quat. Sci. Rev. 26, 37-55 (2007).

12. Huybers, P. Combined obliquity and precession pacing of late Pleistocene deglaciations. Nature 480, 229-232 (2011).

13. Ganopolski, A. \& Calov, R. The role of orbital forcing, carbon dioxide and regolith in 100 kyr glacial cycles. Clim. Past 7, 1415-1425 (2011).

14. Imbrie, I. Z., Imbrie-Moore, A. \& Lisiecki, L. E. A phase-space model for Pleistocene ice volume. Earth Planet. Sci. Lett. 307, 94-102 (2011).

15. Parrenin, F. \& Paillard, D. Terminations VI and VIII ( $\sim 530$ and $\sim 720 \mathrm{kyr}$ BP) tell us the importance of obliquity and precession in the triggering of deglaciations. Clim. Past 8, 2031-2037 (2012).

16. Ashwin, P. \& Ditlevsen, P. The middle Pleistocene transition as a generic bifurcation on a slow manifold. Clim. Dyn. 45, 2683-2695 (2015).

17. Shackleton, N. Oxygen isotope analyses and Pleistocene temperatures re-assessed. Nature 215, 15-17 (1967).

18. Shackleton, N. J. \& Opdyke, N. D. Oxygen isotope and palaeomagnetic stratigraphy of equatorial Pacific core V28-238: oxygen isotope temperatures and ice volumes on a $10^{5}$ and $10^{6}$ year scale. Quat. Res. 3, 39-55 (1973).

19. Past Interglacial Working Group of PAGES. Interglacials of the last 800,000 years. Rev. Geophys. 54, 162-219 (2016).

20. Lisiecki, L. E. \& Raymo, M. E. A Pliocene-Pleistocene stack of 57 globally distributed benthic $\delta^{18} \mathrm{O}$ records. Paleoceanography 20, PA1003 (2005).

21. Huybers, P. Early Pleistocene glacial cycles and the integrated summer insolation forcing. Science 313, 508-511 (2006). 
22. Bounceur, N., Crucifix, M. \& Wilkinson, R. D. Global sensitivity analysis of the climate-vegetation system to astronomical forcing: an emulator-based approach. Earth Syst. Dynam. 6, 205-224 (2015).

23. Raymo, M. E. \& Nisancioglu, K. The 41 kyr world: Milankovitch's other unsolved mystery. Paleoceanography 18, PA2011 (2003).

24. Shackleton, N. J., Berger, A. \& Peltier, W. R. An alternative astronomical calibration of the lower Pleistocene timescale based on ODP Site 677. Trans. R. Soc. Edinb. Earth Sci. 81, 251-261 (1990).

25. Raymo, M. E. The timing of major climate terminations. Paleoceanography 12, 577585 (1997)

26. Lang, N. \& Wolff, E. W. Interglacial and glacial variability from the last $800 \mathrm{ka}$ in marine, ice and terrestrial archives. Clim. Past 7, 361-380 (2011).

27. MacAyeal, D. R. A catastrophe model of the paleoclimate. J. Glaciol. 24, 245-257 (1979).

28. Birchfield, G. E., Weertman, J. \& Lunde, A. T. A paleoclimate model of Northern Hemisphere ice sheets. Quat. Res. 15, 126-142 (1981).

29. Pollard, D. A coupled climate-ice-sheet model applied to the Quaternary ice ages. $J$. Geophys. Res. Oceans 88, 7705-7718 (1983).

30. Abe-Ouchi, A. et al. Insolation-driven 100,000-year glacial cycles and hysteresis of ice-sheet volume. Nature 500, 190-193 (2013).

31. Bouttes, N. et al. Impact of oceanic processes on the carbon cycle during the last termination. Clim. Past 8, 149-170 (2012).

32. Hodell, D. A. \& Channell, J. T. Mode transitions in Northern Hemisphere glaciation: co-evolution of millennial and orbital variability in Quaternary climate. Clim. Past 12, 1805-1828 (2016).

33. Lawrence, K. T., Sosdian, S., White, H. E. \& Rosenthal, Y. North Atlantic climate evolution through the Plio-Pleistocene climate transitions. Earth Planet. Sci. Lett. 300, 329-342 (2010).

34. Naafs, B. D. A. et al. Strengthening of North American dust sources during the late Pliocene (2.7 Ma). Earth Planet. Sci. Lett. 317-318, 8-19 (2012). 
35. Hodell, D. A. \& Venz-Curtis, K. A. Late Neogene history of deepwater ventilation in the Southern Ocean. Geochem. Geophys. Geosyst. 7, Q09001 (2006).

36. Lisiecki, L. E. Atlantic overturning responses to obliquity and precession over the last 3 Myr. Paleoceanography 29, 71-86 (2014).

37. Shackleton, N. J. \& Opdyke, N. D. Oxygen-isotope and paleomagnetic stratigraphy of Pacific core V28-239: late Pliocene to latest Pleistocene. Geol. Soc. Am. 145, 449464 (1976).

38. Pisias, N. G. \& Moore, T. C., Jr. The evolution of Pleistocene climate: a time series approach. Earth Planet. Sci. Lett. 52, 450-458 (1981).

39. Ruddiman, W. F., Raymo, M. \& McIntyre, A. Matuyama 41,000-year cycles: North Atlantic Ocean and Northern Hemisphere ice sheets. Earth Planet. Sci. Lett. 80, 117 129 (1986).

40. Maasch, K. A. Statistical detection of the mid-Pleistocene transition. Clim. Dyn. 2, 133-143 (1988).

41. Clark, P. U. et al. The middle Pleistocene transition: characteristics, mechanisms, and implications for long-term changes in atmospheric $\mathrm{pCO}_{2}$. Quat. Sci. Rev. 25, 3150$3184(2006)$.

42. Martínez-Garcia, A. et al. Southern Ocean dust-climate coupling over the past four million years. Nature 476, 312-315 (2011).

43. McClymont, E., Sosdian, S. M., Rosell-Melé, A. \& Rosenthal, Y. Pleistocene seasurface temperature evolution: early cooling, delayed glacial intensification, and implications for the mid-Pleistocene climate transition. Earth Sci. Rev. 123, 173-193 (2013).

44. Head, M. J. \& Gibbard, P. L. Early-Middle Pleistocene transitions: linking terrestrial and marine realms. Quat. Int. 389, 7-46 (2015).

45. Elderfield, H. et al. Evolution of ocean temperature and ice volume through the midPleistocene climate transition. Science 337, 704-709 (2012).

46. Ehlers, J., Gibbard, P. L. \& Hughes, P. D. (eds) Quaternary Glaciations - Extent and Chronology. A Closer Look (Developments in Quaternary Sciences Vol. 15, Elsevier, 2011). 
47. Maslin, M. A. \& Brierley, C. M. The role of orbital forcing in the Early Middle Pleistocene Transition. Quat. Int. 389, 47-55 (2015).

48. Berger, W. H. \& Jansen, E. in The Polar Oceans and Their Role in Shaping the Global Environment (eds Johannessen, O. M. et al.) 295-311 (Geophysical Monograph Series Vol. 84, American Geophysical Union, 1994).

49. Tziperman, E. \& Gildor, H. On the mid-Pleistocene transition to 100-kyr glacial cycles and the asymmetry between glaciation and deglaciation times.

Paleoceanography 18, 1001 (2003).

50. Laskar, J. et al. A long-term numerical solution for the insolation quantities of the Earth. Astron. Astrophys. 428, 261-285 (2004).

Supplementary Information is available in the online version of the paper.

Acknowledgements We thank D. A. Hodell, S. J. Crowhurst, M. A. Maslin, L. C. Skinner, L. Cannings and members of the PAGES Working Groups on Past Interglacials (PIGS) and Quaternary Interglacials (QUIGS) for discussions. P.C.T. acknowledges funding from a Leverhulme Trust Research Project Grant (RPG-2014-417). M.C. and T.M. acknowledge support from the Belgian Policy Office under contract BR/121/A2/STOCHCLIM. E.W.W. is funded under a Royal Society Research Professorship and M.C. is a senior research scientist with the Belgian National Fund of Scientific Research. This is a contribution to PAGES QUIGS.

Author Contributions P.C.T. led the study and the writing of the paper with contributions from E.W.W., M.C. and T.M. M.C. and T.M. developed the methodology and performed the statistical analyses. E.W.W. led the development of the interglacial taxonomy. All authors contributed equally to the ideas in this paper.

Author Information Reprints and permissions information is available at www.nature.com/reprints. The authors declare no competing financial interests. Readers are welcome to comment on the online version of the paper. Correspondence and requests for materials should be addressed to P.C.T. (p.c.tzedakis@ucl.ac.uk).

Reviewer Information Nature thanks D. Paillard and the other anonymous reviewer(s) for their contribution to the peer review of this work.

Figure 1 | Occurrence of interglacials over the past 800,000 years. a, LR04 benthic $\delta^{18} \mathrm{O}$ $\operatorname{stack}^{20} . \mathbf{b}$, Daily mean insolation on 21 June at $65^{\circ} \mathrm{N}$ (ref. 50). Marine Isotope sub-Stages (MIS), corresponding to benthic $\delta^{18} \mathrm{O}$ minima, are indicated. Black arrows denote interglacials ${ }^{19}$.

Figure 2 | Interglacials, continued interglacials and interstadials in relation to caloric summer half-year insolation over the past 2.6 Myr. a, 1,980-2,660 kyr BP. b, 1,3202,000 kyr BP. c, 660-1,340 kyr BP. d, 0-680 kyr BP. (Note age overlap between panels.) The orange line shows the LR04 benthic $\delta^{18} \mathrm{O} \operatorname{stack}^{20}$. The black line is the caloric summer half- 
year insolation at $65^{\circ} \mathrm{N}$, calculated from the orbital solution of ref. 50 (Methods). Periods of above-average obliquity are shaded in grey. On the insolation curve, each peak is coded according to the classification in Supplementary Table 1: red circles, insolation maxima nearest to the onset of interglacials; black diamonds, continued interglacials; light blue triangles, interstadials; open symbols indicate uncertainty in the assignments. The vertical black lines represent the onset of interglacials, determined as the point at which the benthic isotope record crosses a threshold (Methods). Either MIS or ages of insolation peaks (kyr BP) are shown at the top of each panel for the onset of interglacials, or at the bottom of each panel for continued interglacials and interstadials.

Figure 3 | Caloric summer half-year insolation peaks over the past 2.6 Myr. Each insolation peak is plotted according to the classification as the onset of an interglacial (red circles), a continued interglacial (black diamonds) or an interstadial (light blue triangles), as in Supplementary Table 1; open symbols correspond to uncertain assignments. The horizontal dashed line shows that, before $1 \mathrm{Myr}$ BP, an insolation threshold (of about $5.945 \mathrm{GJ} \mathrm{m}^{-2}$ ) separating interglacials and continued interglacials from interstadials can be delineated with very few exceptions. The labels on the data correspond to either MIS or ages of insolation peaks (kyr BP).

\section{Figure 4 | Caloric summer half-year insolation peaks against time since the onset of the} previous interglacial over the past 1 Myr. The diagonal line separates insolation peaks associated with the onset of interglacials (red circles) from those associated with a continued interglacial (black diamond) and interstadials (light blue triangles). This line has a decreasing slope of $0.0021 \pm 0.0001 \mathrm{GJ} \mathrm{m}^{-2} \mathrm{kyr}^{-1}$ and is derived as the 50th percentile of having an interglacial onset in the statistical model calibrated over the past $1 \mathrm{Myr}$ (Methods); the grey strip indicates the 25 th-75th percentiles. The labels on the data correspond to either MIS or ages of insolation peaks (kyr BP).

Figure 5 | Effective energy at each insolation peak during the past 2.6 Myr. The effective energy is defined in equation (1), and the discount rate of $0.002107 \mathrm{GJ} \mathrm{m}^{-2} \mathrm{kyr}^{-1}$ is chosen as the maximum a posteriori probability estimate of the statistical model calibrated over the past 2.6 Myr (Methods). Each insolation peak is plotted according to the classification as the onset of an interglacial (red circles), a continued interglacial (black diamonds) or an interstadial (light blue triangles), as in Supplementary Table 1; open symbols correspond to uncertain assignments. The two horizontal lines with a ramp in between show that the simple model is 
very successful in separating complete deglaciations from incomplete and no deglaciations (see text). The ramp is drawn according to the maximum a posteriori probability estimate of the statistical model (Methods and Extended Data Fig. 10). The labels on the data correspond to either MIS or ages of insolation peaks (kyr BP).

\section{Figure 6 | Simulations of the most probable sequences of interglacials over the past}

1 Myr. a, Actual sequence of interglacials. b, Sequence with absence of complete deglaciation at MIS 7c. c, Sequence with absence of complete deglaciation at MIS 11c. d, Sequence with complete deglaciation at MIS 3. The probabilities of occurrence of each scenario (left) are estimated on the basis of the calibrated Bayesian logistic regression (Methods). Red circles, black diamonds and light blue triangles denote the actual occurrence of the onset of interglacials, continued interglacials and interstadials, respectively. Vertical bars indicate complete deglaciations according to each scenario. Yellow bands denote intervals where the sequence of interglacials is modified. The labels on the axes correspond to either MIS or ages of insolation peaks (kyr BP).

\section{METHODS}

\section{Definition of interglacials}

According to a recent review ${ }^{19}$, an objective criterion for an interglacial is the absence of substantial Northern Hemisphere ice outside Greenland. This criterion is supported by the observation $^{45}$ that when the ice-volume component of a benthic oxygen isotope record was separated from the deep-water-temperature component, it reached close to the modern value in all the prominent isotopic highstands of the past 1.5 Myr.

Assuming that there is little difference in Antarctic ice volume between interglacials, this criterion equates to a sea-level definition. Looking at only the past $800 \mathrm{kyr}$, it was proposed $^{19}$ that an interglacial occurred if sea level reached above $-20 \mathrm{~m}$ compared to the present-day level. It was also suggested that, to be considered a separate interglacial, sea level must pass below a second valley threshold on either side of the peak ${ }^{19}$.

This definition suggests a roster of 11 interglacials since 800 kyr BP (Fig. 1) ${ }^{19}$. However, differences between sea-level reconstructions left ambiguity. To obtain a more robust result, sensitivity studies were carried out using the LR04 benthic isotope stack ${ }^{20}$. This has the disadvantage that it contains a component of deep-water temperature as well as ice volume, but the advantage that it is based on many datasets and is therefore robust against the appearance of new data. Using LR04, it was found that a wide range of thresholds $\left(\delta^{18} \mathrm{O}\right.$ 
between $3.5 \%$ and $3.73 \%$ ) led to the same roster of interglacials ${ }^{19}$. This confirms that, for the past $800 \mathrm{kyr}$, there is a clear gap between the population of interglacials and the population of interstadials. No threshold was specified for the depth of the 'valley' that would distinguish two separate interglacials from a continuing one. However, MIS $15 \mathrm{~b}$ was considered to to separate two interglacials, whereas MIS 7b was not; this puts limits on the acceptable valley depth.

In the earlier part of the Quaternary, there are not sufficiently precise sea-level data to attempt to choose an interglacial roster on the basis of sea level, so we are forced to use benthic isotope records. The main benthic record we use is the LR04 stack $^{20}$, which consists of 57 datasets, although the number is substantially fewer in the first part of the Quaternary compared to the past $800 \mathrm{kyr}$. The resolution of the LR04 record changes for increasing age: it is $1 \mathrm{kyr}$ for $0-600 \mathrm{kyr} \mathrm{BP}, 2 \mathrm{kyr}$ for $600-1,500 \mathrm{kyr} \mathrm{BP}$, and $2.5 \mathrm{kyr}$ before that. To ensure that our interglacial definitions are comparable along the record, we used a smoothed version (to 2-kyr resolution) of LR04 between $0 \mathrm{kyr}$ BP and $600 \mathrm{kyr}$ BP. This has the effect of ensuring that very short (1 kyr) excursions cannot be interpreted as interglacials.

Before $800 \mathrm{kyr}$ BP in LR04 there is no longer a range of values that clearly separates the interglacial and interstadial population, forcing us to choose a set threshold. An estimate of sea level ${ }^{45}$ clearly suggests that most isotopic lows between MIS 21 and 49 should be defined as interglacials. This requires that the threshold between interglacials and interstadials needs to be towards the high end of the 3.50\%- $-3.73 \%$ range used previously. At $3.73 \%$ we are uncomfortably close to making MIS 5c (minimum 3.75\%) an interglacial, despite strong evidence $^{19}$ that it was an interstadial. At $3.71 \%$ we would exclude MIS 27, and at 3.66\%o MIS 33. There is then a gap until beyond 3.58\%o (at which MIS 41 would be excluded, followed closely by others). We must therefore choose where we place the threshold between $3.73 \%$ and 3.58\%, and our choice determines the assignment of MIS 27 and 33.

LR04 has the drawback that in periods in which the underlying data are poorly resolved or the age matching between records is uncertain, the amplitude of peaks could be reduced. Therefore, in addition to the averaged LR04 curve, we also looked at two marine sequences covering this period. One dataset is the composite record (referred to as S05) of Eastern Equatorial Pacific sites: V19-30 (0-341 kyr BP) ${ }^{51}$, V19-28 (341-430 kyr BP $)^{52}$, V1925 (430-460 kyr BP) (N. J. Shackleton, unpublished data), ODP 677 (460-1,809 kyr BP) ${ }^{24}$ and ODP $846(1,812-2,600 \mathrm{kyr} \mathrm{BP})^{53}$. The other dataset is a new well-resolved record U1308 (ref. 32) from the North Atlantic. Although MIS 27 is a very weak peak in both these records, 
MIS 33 is very clear, especially in U1308, in which it is stronger than several peaks that we have classed as interglacial. For this reason, we chose to set the threshold at 3.68\%, thus defining MIS 33 as interglacial and MIS 27 as interstadial. This choice of threshold allows us to apply an objective and consistent method to derive our taxonomy; other choices could have been made, leading to a different population of interglacials.

For ages less than 1.5 Myr BP, establishing the valley depth needed to define separate interglacials was relatively straightforward. The distinction is important because the climate dynamics involved in the transition from a glacial to an interglacial are different from those involved in maintaining an existing ice-free status. On the basis of the past $800 \mathrm{kyr}$, this valley threshold could fall anywhere between 3.82\%o and 4.32\%o without changing the roster of interglacials (either dividing MIS 7a and 7c or combining MIS 15a with 15c-e). The lower amplitude of cycles in the earlier part of the Pleistocene requires a low threshold for valley depth to avoid classifying long sequences of data as interglacial, so we adopt a value of $3.92 \%$ (only $0.24 \%$ above the interglacial threshold).

Before 1.5 Myr BP, there is a clear trend in isotopic values in LR04 and other benthic isotope records over the earlier part of the record. Because this applies also to the 'peaks' (lowest $\delta^{18} \mathrm{O}$ values), yet Northern Hemisphere ice volume cannot be negative, it suggests that the trend is due to other factors: an increase in deep-water temperatures or a decrease in Antarctic ice volume. We therefore detrend LR04 linearly before 1.5 Myr BP (Extended Data Fig. 1a, b) - an age chosen because it appears that deep-water temperature in interglacials did not increase between 1.5 Myr BP and 1 Myr BP (ref. 45). The detrended values are calculated as

$$
\delta^{18} \mathrm{O}^{\prime}= \begin{cases}\delta^{18} \mathrm{O} & \text { for } 0 \leq A \leq 1,500 \\ \delta^{18} \mathrm{O}+3.296 \times 10^{-4}(A-1,500) & \text { for } 1,500<A \leq 2,600\end{cases}
$$

where $A$ is the age (kyr BP).

We maintain the same thresholds (3.68\%o and 3.92\%o) for the detrended record. For each insolation maximum, we seek an obvious minimum in LR04 that falls either just before, or within $10 \mathrm{kyr}$ after, the insolation maximum. The reason for allowing this wide range is twofold: (i) we expect a lag of ice volume behind the insolation forcing by a few thousand years, but the tuning of LR04 to an insolation target is sufficiently imprecise that occasionally it will slightly lead the insolation, and may lag by as much as $10 \mathrm{kyr}$; (ii) if there is no noticeable peak within this range then we assess the value of the LR04 data at the insolation 
maximum itself. This will apply only in the case of some continued interglacials, for which we have to decide whether the system is still in an interglacial state at the insolation maximum that follows the one that caused deglaciation.

In the earlier part of the record ( $>1.5 \mathrm{Myr} \mathrm{BP})$, this method leads to serveral borderline cases. To assess these we again referred to the two discrete records, S05 and U1308. We use the S05 composite record by detrending it linearly before $1.5 \mathrm{Myr}$ BP, as in the case of the LR04 record (Extended Data Fig. 1c, d). The detrended values for S05 are calculated as $\delta^{18} \mathrm{O}^{\prime}= \begin{cases}\delta^{18} \mathrm{O} & \text { for } 0 \leq A \leq 1,500 \\ \delta^{18} \mathrm{O}+4.968 \times 10^{-4}(A-1,500) & \text { for } 1,500<A \leq 2,600\end{cases}$

We set the thresholds $3.88 \%$ and $4.12 \%$ for the detrended S05 record, maintaining the difference of $0.24 \%$ as in LR04.

We used U1308 qualitatively to assess the status of any peak that is borderline in LR04. In assigning interglacial status we give LR04 primacy, because it consists of several marine records, carefully combined (Supplementary Table 1). For borderline cases in LR04 (within $0.04 \%$ of the interglacial threshold) we applied the following criteria: if both S05 and U1308 agree with LR04 (or if one agrees and the other is also borderline), then the assignment is confirmed; if one agrees and one clearly disagrees, then we retain the LR04 assignment but treat it as uncertain (open symbol in our figures); or, if both disagree with LR04, then we overturn the assignment but treat it as uncertain. Supplementary Table 1 shows all the uncertain assignments and our reasoning, with those $\delta^{18} \mathrm{O}$ peaks especially discussed shown enlarged in Extended Data Figs 2 and 3. We discuss some examples below.

For MIS 61 (insolation peak at 1,739 kyr BP), LR04 only marginally exceeds the threshold as an interglacial (Extended Data Fig. 2). The value is below the threshold in S05 (Extended Data Fig. 3), but the peak in U1308 is reasonably strong, so the peak is classed as interglacial but uncertain (Supplementary Table 1). In LR04, MIS 67 is a continuation of MIS 69 rather than a separate interglacial - even a tiny change in the separation threshold of $3.92 \%$ would have overturned this classification. In this case, U1308 agrees with no separation, whereas there is clear separation in S05, which questions this assignment. We assigned MIS 67 as a continued interglacial but uncertain (Supplementary Table 1). MIS 71 would not be classed as interglacial in LR04; it is not especially weak in either S05 or U1308, and for that reason we classed it as an uncertain interglacial even though it just fails the test in 
LR04 (Supplementary Table 1). We recommend caution for any conclusions that rely on these assignments.

One interglacial, MIS 59, requires a special discussion. In all of LR04, S05 and U1308 there is a clear interglacial peak after the insolation peak at 1,697 kyr BP, but well before the next one at 1,663 kyr BP. However, our threshold is first passed only $11 \mathrm{kyr}$ (LR04) and 14 kyr (S05) after the insolation peak, outside the criterion we set (Extended Data Figs 2 and 3). Nonetheless, given that there is no other possible match of insolation peak to a LR04/S05 minimum, we assume that this large lag results either from the fact that the insolation peak is wide, with a shoulder near the databased interglacial maximum, or from a tuning issue in the age models. We therefore classed the insolation peak at 1,697 kyr BP as being associated with an interglacial (Supplementary Table 1).

Finally, we note that the only interval of above-average obliquity before $1 \mathrm{Myr}$ BP that is not associated with an interglacial or a continued interglacial is the one containing the insolation peak at 2,062 kyr BP, which is classified as a definite interstadial. However, despite the clear assignment in LR04 (which is given primacy in our classification scheme), $2,062 \mathrm{kyr}$ BP is classified as a clear interglacial in S05. Because the position of the diagonal line separating interglacials from interstadials and continued interglacials in Extended Data Fig. $5 \mathrm{~b}$ (and of the horizontal line on the right-hand side of Fig. 5) is constrained by the insolation peak at 2,062 kyr BP, this is one part of the record for which further data are required.

The outcome of all of this discussion is that every insolation maximum is classed as associated with an interglacial, a continued interglacial or an interstadial (although in some cases no obvious interstadial peak is visible). In a small number of cases, these assignments are classed as uncertain. Our classification is firm according to the rules we have set, but other rules would change some of the assignments, particularly those classed as uncertain.

\section{Insolation data}

The insolation data shown in the figures and Supplementary Tables 1 and 2 are based on the algorithm for computing astronomical parameters ${ }^{50}$, available in the software package palinsol $^{54}$, developed for $\mathrm{R}$. The solar constant used is $1,368 \mathrm{~W} \mathrm{~m}^{-2}$.

\section{Statistical model}

The odds of a deglaciation obey a logistic model: 
$\log [P /(1-P)]=\beta_{0}+\beta_{1} I_{\text {peak }}+\beta_{2} \Delta t$

with $P$ the probability of an interglacial onset, $I_{\text {peak }}$ the peak summer caloric insolation and $\Delta t$ the time since the onset of the previous interglacial. Although the model is calibrated under this form using Jeffrey's priors for $\beta_{0}, \beta_{1}$ and $\beta_{2}$ (ref. 55), it can be rewritten as

$$
\log [P /(1-P)]=\left[I_{\text {peak }}+b \Delta t-E_{0}\right] / \sigma
$$

with $\sigma=1 / \beta_{1}, E_{0}=-\beta_{0} \sigma$ and $b=\beta_{2} \sigma$, where $b$ is the discount rate and $E_{0}$ is the deglaciation threshold. The parameter $\sigma$ is a measure of stochasticity. In the limit $\sigma \rightarrow \infty$, all events occur with a probability of $50 \%$. In the limit $\sigma \rightarrow 0$, all events occur with a probability of 1 or 0 , depending on whether the effective energy exceeds the deglaciation threshold $E_{0}$ or not. The system is then deterministic. Jeffrey's prior puts more weight on large values of $\sigma$, which means that deglaciation events are a priori stochastic. The likelihood associated with one observation is then $P$ if this observation is an interglacial onset, and $1-P$ otherwise. If the observation is treated as uncertain (see text) —we assign a $10 \%$ probability of misattribution whether or not the observation is an interglacial onset - then the likelihood is $0.9 P+0.1(1-P)$ for an interglacial onset, and $0.1 P+0.9(1-P)$ otherwise.

One recommendation ${ }^{55}$ is to seek the posterior maximum, and then estimate the posterior distribution by importance sampling to improve on the Laplacian approximation. We found this procedure problematic, especially with the ramp model (see below), because several local maxima may exist. We instead estimated the maximum posterior and used the Hessian matrix to build a proposal for a Metropolis Hastings posterior sampling. We ran 40 Metropolis Hastings Markov chains. Each chain was skimmed to suppress sample autocorrelations, and the 40 chains were combined with weights equal to their respective marginal likelihoods (estimated using truncated harmonic means, following ref. 56). The resulting parameter distributions were then sampled to estimate plausible histories over the past $1 \mathrm{Myr}$.

We generalize the model as follows for application over the past 2.6 Myr. The deglaciation threshold $E_{0}$ changes linearly between two dates denoted $A_{1}$ and $A_{2}$, with the difference in threshold between ages $A_{1}$ and $A_{2}$ equal to $\Delta E$ (see Fig. 5). The model is then $\log \left[\mathrm{P} /(1-\mathrm{P}]=\beta_{0}+\beta_{1}\left[I_{\text {peak }}+\operatorname{ramp}(A) \Delta E\right]+\beta_{2} \Delta \mathrm{t}\right.$ where $\operatorname{ramp}(A)$ is a $\operatorname{ramp}$ function: 
$\operatorname{ramp}(A)= \begin{cases}0 & \text { for } A \leq A_{1} \\ \frac{A-A_{1}}{A_{2}-A_{1}} & \text { for } A_{1}<A<A_{2} \\ 1 & \text { for } A \geq A_{2}\end{cases}$

$A_{1}$ and $A_{2}$ are parameterized as follows:

$A_{1}=A_{\text {mid }}-\frac{\Delta A}{2} ; \quad A_{2}=A_{\text {mid }}+\frac{\Delta A}{2}$

We adopt uniform priors for $\Delta E, A_{\text {mid }}$ and $\Delta A$.

We find the discount rate $b$ to be the same (within uncertainties) regardless of whether the model is calibrated only over the past $1 \mathrm{Myr}$ (Fig. 4) or over the past 2.6 Myr with the ramp function (Extended Data Fig. 5). The posterior distribution of $A_{1}$ and $A_{2}$ are shown in Extended Data Fig. 10.

\section{Modelling results based on the summer solstice mean daily insolation at $65^{\circ} \mathrm{N}$}

In the main text we discussed a model for the occurrence of interglacial onsets based on the caloric summer half-year insolation ${ }^{1}$ at $65^{\circ} \mathrm{N}$, calculated from the orbital solution of ref. 50 . Extended Data Figs 6-9 show the model results obtained by using the summer solstice mean daily insolation at $65^{\circ} \mathrm{N}$ (ref. 50) instead. Whereas the caloric summer half-year insolation at $65^{\circ} \mathrm{N}$ has almost equal contributions from precession and obliquity, the summer solstice mean daily insolation at $65^{\circ} \mathrm{N}$ has $80 \%$ of its variance in the precession band. The summer solstice insolation curve at $65^{\circ} \mathrm{N}$ over the past 2.6 Myr is presented as the black curve in Extended Data Fig. 6. The red, black and light blue symbols indicate the summer solstice insolation maxima nearest to the interglacial onsets, continued interglacials and interstadials, respectively. They are classified by the same criteria explained in Methods section 'Definition of interglacials'. Results are listed in Supplementary Table 2. In about 90\% of cases, summer solstice insolation maxima occur near $( \pm 5 \mathrm{kyr})$ caloric summer insolation maxima, but the former has additional peaks due to the stronger precession component; for example, a single peak at $51 \mathrm{kyr}$ BP in the caloric summer insolation at $65^{\circ} \mathrm{N}$ is split into two peaks at $38 \mathrm{kyr}$ BP and $58 \mathrm{kyr}$ BP in the summer solstice insolation at $65^{\circ} \mathrm{N}$.

Peak summer solstice insolation for interglacials, continued interglacials and interstadials is plotted as a function of age in Extended Data Fig. 7. Unlike caloric summer insolation (Fig. 3), it is difficult to draw a simple summer solstice insolation threshold that separates interglacials from interstadials before $1 \mathrm{Myr}$ BP. According to our model, an 
interglacial onset occurs when a peak insolation exceeds a threshold line that decreases with time since the previous deglaciation (the slope of the line is referred to as the 'discount rate' of the insolation required for deglaciation). Extended Data Fig. 8 shows the peak summer solstice insolation at $65^{\circ} \mathrm{N}$ as a function of the time since the onset of the previous interglacial during the time intervals 0-1 Myr BP (Extended Data Fig. 8a), 1-1.5 Myr BP (Extended Data Fig. 8b, inset) and 1.5-2.6 Myr BP (Extended Data Fig. 8b). Whereas in the past $1 \mathrm{Myr}$ it is possible to define an optimum threshold line (dashed line in Extended Data Fig. 8a) with one false negative (MIS 11c) and one false positive (979 kyr BP), any straight threshold line before 1.5 Myr BP produces several false positives or a combination of false positives and false negatives. The effective energy at each summer solstice insolation peak is calculated according to equation (1), but with a discount rate of $0.575 \mathrm{~W} \mathrm{~m}^{-2} \mathrm{kyr}^{-1}$, estimated from Extended Data Fig. 8a.

A complete deglaciation occurs when this effective energy exceeds the deglaciation threshold $E_{0}$ (indicated by the $y$ intercept of the diagonal line in Extended Data Fig. 8a). Extended Data Fig. 9 shows the effective energy at each insolation peak as a function of age, underlining the absence of a simple threshold in effective energy before $1 \mathrm{Myr}$ BP. These results suggest that summer solstice insolation at $65^{\circ} \mathrm{N}$ is a weaker predictor of interglacials than the caloric summer half-year insolation at $65^{\circ} \mathrm{N}$.

\section{Data availability}

The benthic isotope records and insolation data analysed in this study and the code to reproduce the experiments are available from https://github.com/mcrucifix/logistic insol

51. Shackleton, N. J. \& Pisias, N. G. in The Carbon Cycle and Atmospheric $\mathrm{CO}_{2}$ : Natural Variations Archean to Present (eds Sundquist, E. T \& Broecker, W. S.) 303-317 (Geophysical Monograph Series Vol. 32, American Geophysical Union, 1985).

52. Ninkovich, D. \& Shackleton, N. J. Distribution, stratigraphic position and age of ash layer "L", in the Panama Basin region. Earth Planet. Sci. Lett. 27, 20-34 (1975).

53. Shackleton, N. J., Hall, M. A. \& Pate, D. Pliocene stable isotope stratigraphy of Site 846. In Proc. Ocean Drilling Program, Scientific Results Vol. 138 (eds Pisias, N. G. et al.) 337-355 (Ocean Drilling Program, 1995).

54. Crucifix, M. Palinsol: insolation for palaeoclimate studies, R package version 0.93, https://bitbucket.org/mcrucifix/insol (2016). 
55. Chen, M.-H., Ibrahim, J. G. \& Kim, S. Properties and implementation of Jeffreys's prior in binomial regression models. J. Am. Stat. Assoc. 103, 1659-1664 (2008).

56. Robert, C. P. \& Wraith, D. Computational methods for Bayesian model choice. AIP Conf. Proc. 1193, 251-262 (2009).

\section{Extended Data Figure 1 | Definition of interglacial onsets in LR04 and S05. a, LR04}

1,300-2,600 kyr BP (original record in black, detrended record in red). The linear trend over the period 1,500-2,600 kyr BP is removed in the detrended record (Methods). An interglacial onset is identified when the detrended value of $\delta^{18} \mathrm{O}$ falls below the lower threshold of $3.68 \%$ o (upper dashed line) after once being above the higher threshold of 3.92\%o (lower dashed line) (Methods). b, LR04 record 0-1,300 kyr BP. c, S05 record 1,300-2,600 kyr BP (original record in black, detrended record in red). The linear trend over the period 1,500-2,600 kyr BP is removed in the detrended record (Methods). An interglacial onset is identified when the detrended value of $\delta^{18} \mathrm{O}$ falls below the lower threshold of $3.88 \%$ (upper dashed line) after once being above the higher threshold of 4.12\% (lower dashed line) (Methods). d, S05 record 0-1,300 kyr BP. In all panels, the light blue circles indicate the first data point after the interglacial onset.

\section{Extended Data Figure 2 | Examples of classification of caloric summer insolation peaks}

based on the detrended LR04 record. Shown are cases for which (i) the detrended $\delta^{18} \mathrm{O}^{\prime}$ is near a threshold, (ii) the insolation peak is classified as a continued interglacial, or (iii) the classification result is different between the LR04 and S05 records. Each panel shows changes in detrended $\delta^{18} \mathrm{O}^{\prime}(\%)$ of the LR04 record as a function of age (kyr BP). The timing of caloric summer insolation peaks is indicated by a vertical line at the centre of each panel. For each insolation peak, we seek an obvious minimum in the detrended $\delta^{18} \mathrm{O}^{\prime}$ that falls either just before, or within $10 \mathrm{kyr}$ after, the insolation peak. An insolation peak is associated with an interglacial if the detrended $\delta^{18} \mathrm{O}^{\prime}$ minimum is below 3.68\%o (upper dashed line). The insolation peak associated with an interglacial is then classified as an interglacial onset if there is a detrended $\delta^{18} \mathrm{O}^{\prime}$ value higher than 3.92\%o (lower dashed line) between the current interglacial state and the previous interglacial state. Otherwise, it is classified as a continued interglacial. An insolation peak is associated with an interstadial if the obvious minimum in detrended $\delta^{18} \mathrm{O}^{\prime}$ does not pass the lower threshold of 3.68\%. See Supplementary Table 1 for details. Red, black and light blue labels indicate interglacial onsets, continued interglacials 
and interstadials, respectively. The labels above each panel correspond to either MIS or ages of insolation peaks (kyr BP).

\section{Extended Data Figure 3 | Examples of classification of caloric summer insolation peaks}

based on the detrended $\mathrm{S05}$ record. Shown are cases for which (i) the detrended $\delta^{18} \mathrm{O}^{\prime}$ is near a threshold, (ii) the insolation peak is classified as a continued interglacial, or (iii) the classification result is different between the LR04 and S05 records. Each panel shows changes in detrended $\delta^{18} \mathrm{O}^{\prime}(\%)$ of the S05 record as a function of age (kyr BP). The timing of caloric summer insolation peaks is indicated by a vertical line at the centre of each panel. For each insolation peak, we seek an obvious minimum in the detrended $\delta^{18} \mathrm{O}^{\prime}$ that falls either just before, or within $10 \mathrm{kyr}$ after, the insolation peak. An insolation peak is associated with an interglacial if the detrended $\delta^{18} \mathrm{O}^{\prime}$ peak is below 3.88\% (upper dashed line). The insolation peak associated with an interglacial is then classified as an interglacial onset if there is a detrended $\delta^{18} \mathrm{O}^{\prime}$ value higher than 4.12\%o (lower dashed line) between the current interglacial state and the previous interglacial state. Otherwise, it is classified as a continued interglacial. An insolation peak is associated with an interstadial if the obvious minimum in detrended $\delta^{18} \mathrm{O}^{\prime}$ does not pass the lower threshold of 3.88\%o. See Supplementary Table 1 for details. Red, black and light blue labels indicate interglacial onsets, continued interglacials and interstadials, respectively. The labels above each panel correspond to either MIS or ages of insolation peaks (kyr BP).

\section{Extended Data Figure 4 | Illustration of estimating times since previous deglaciation in} the interval MIS 7e-5e. Elapsed time is calculated as the interval from the caloric summer insolation peak nearest to the onset of an interglacial to an ensuing insolation peak, on the assumption that each peak could potentially have led to a complete deglaciation. The orange line shows the LR04 benthic $\delta^{18} \mathrm{O}$ stack $^{20}$. The black line is the caloric summer half-year insolation at $65^{\circ} \mathrm{N}$. The vertical dashed lines indicate the ages of insolation peaks nearest to the onsets of an interglacial. Elapsed times are indicated by double-headed arrows. The labels correspond to either MIS or ages of insolation peaks (kyr BP).

\section{Extended Data Figure 5 | Caloric summer half-year insolation peaks against time since} the previous onset of an interglacial. a, 1-1.5 Myr BP. b, 1.5-2.6 Myr BP. In b, the diagonal line separates insolation peaks associated with interglacial onsets (red circles) from those associated with continued interglacials (black diamonds) and interstadials (light blue triangles). The diagonal line is derived as the 50th percentile of having an interglacial onset in 
the statistical model calibrated over the past 2.6 Myr (Methods); the grey strip for 1.52.6 Myr BP indicates the 25 th-75th percentiles. The slope of the diagonal line is $0.0021 \pm 0.0001 \mathrm{GJ} \mathrm{m}^{-2} \mathrm{kyr}^{-1}$. The labels on the data correspond to either MIS or ages of insolation peaks (kyr BP).

Extended Data Figure 6 | Interglacials, continued interglacials and interstadials in relation to summer solstice mean daily insolation at $65^{\circ} \mathrm{N}$ over the past $2.6 \mathrm{Myr}$. a, 1,980-2,660 kyr BP. b, 1,320-2,000 kyr BP. c, 660-1,340 kyr BP. d, 0-680 kyr BP. (Note age overlap between panels.) The orange line shows the LR04 benthic $\delta^{18} \mathrm{O}$ stack $^{20}$. The black line is the summer solstice mean daily insolation at $65^{\circ} \mathrm{N}$, calculated from the orbital solution of ref. 50 (Methods). Periods of above-average obliquity are shaded in grey. On the insolation curve, each peak is coded according to the classification in Supplementary Table 2: red circles, insolation maxima nearest to the onset of interglacials; black diamonds, continued interglacials; light blue triangles, interstadials; open symbols indicate uncertainty in the assignments. The vertical black lines represent the onset of interglacials, determined as the point at which the benthic isotope record crosses a threshold (Methods). Either MIS or ages of insolation peaks (kyr BP) are shown at the top of each panel for the onset of interglacials, or at the bottom of each panel for continued interglacials and interstadials.

\section{Extended Data Figure $7 \mid 65^{\circ} \mathrm{N}$ summer solstice mean daily insolation peaks over the}

past 2.6 Myr. Each insolation peak is plotted according to the classification as the onset of an interglacial (red circle), a continued interglacial (black diamond) or an interstadial (light blue triangle), as in Supplementary Table 2; open symbols correspond to uncertain assignments. The labels on the data correspond to either MIS or ages of insolation peaks (kyr BP).

\section{Extended Data Figure $8 \mid 65^{\circ} \mathrm{N}$ summer solstice mean daily insolation peaks against} time since the onset of the previous interglacial. a, $0-1$ Myr BP. The diagonal line represents a possible threshold $(567.5-0.575 \times($ elapsed time $))$ that separates insolation peaks associated with the interglacial onsets (red circles) from peaks associated with interstadials (light blue triangles) and a continued interglacial (black diamond), with fewest failures (MIS 11c and 979 kyr BP). b, 1.5-2.6 Myr BP. Inset, 1-1.5 Myr BP. The labels on the data correspond to either MIS or ages of insolation peaks (kyr BP).

Extended Data Figure 9 | Effective energy at each summer solstice mean daily insolation peak over the past 2.6 Myr. The effective energy is defined in equation (1), with a discount rate of $0.575 \mathrm{~W} \mathrm{~m}^{-2} \mathrm{kyr}^{-1}$ estimated from Extended Data Fig. 8a. Each insolation peak is 
plotted according to the classification as the onset of an interglacial (red circles), a continued interglacial (black diamonds) or an interstadial (light blue triangles), as in Supplementary Table 2; open symbols correspond to uncertain assignments. The horizontal dashed line is a possible threshold for a complete deglaciation $\left(567.5 \mathrm{~W} \mathrm{~m}^{-2}\right.$ over the past $\left.1 \mathrm{Myr}\right)$, which separates insolation peaks associated with interglacial onsets (red circles) from the others, with one false negative (MIS 11c) and one false positive (979 kyr BP). The labels on the data correspond to either MIS or ages of insolation peaks (kyr BP).

Extended Data Figure 10 | Estimation of the timing of the Early Pleistocene ramp in the deglaciation threshold. Histogram obtained by Monte Carlo sampling of the posterior distributions $(25,000$ samples $)$ of the parameters of the logistic regression model for the onset of interglacials, using a ramp function as described in Methods. Shown is the timing of the onset versus the end of the ramp function, as displayed in Fig. 5. 


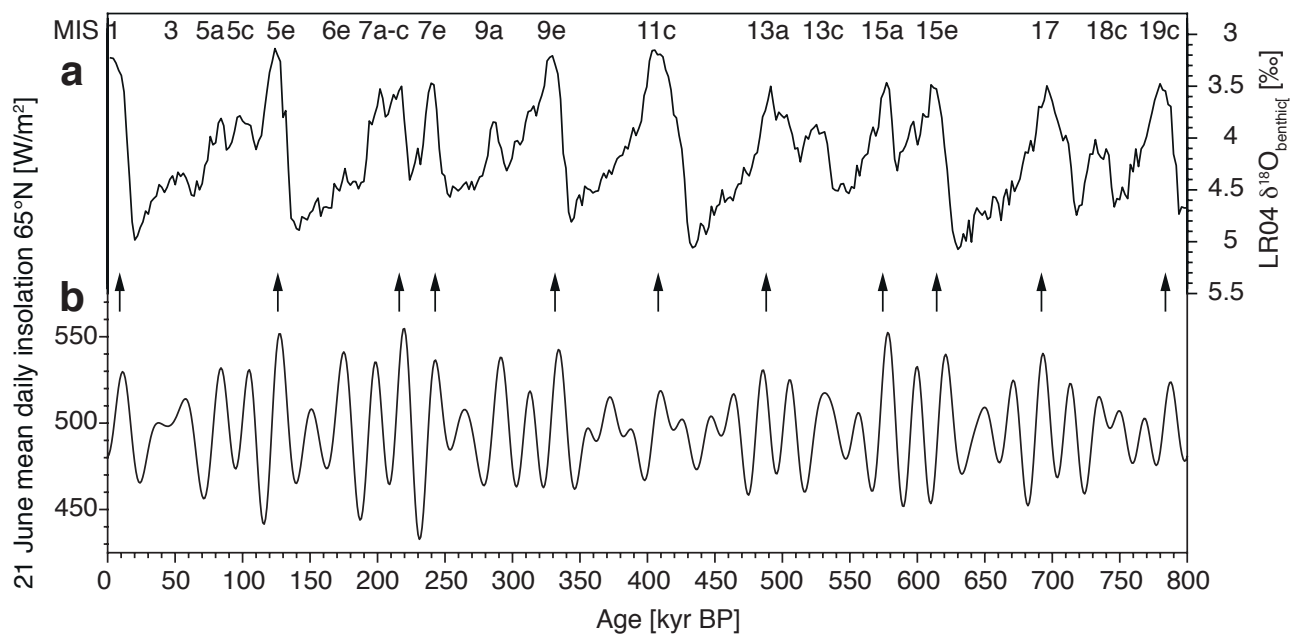

Fig. 1 


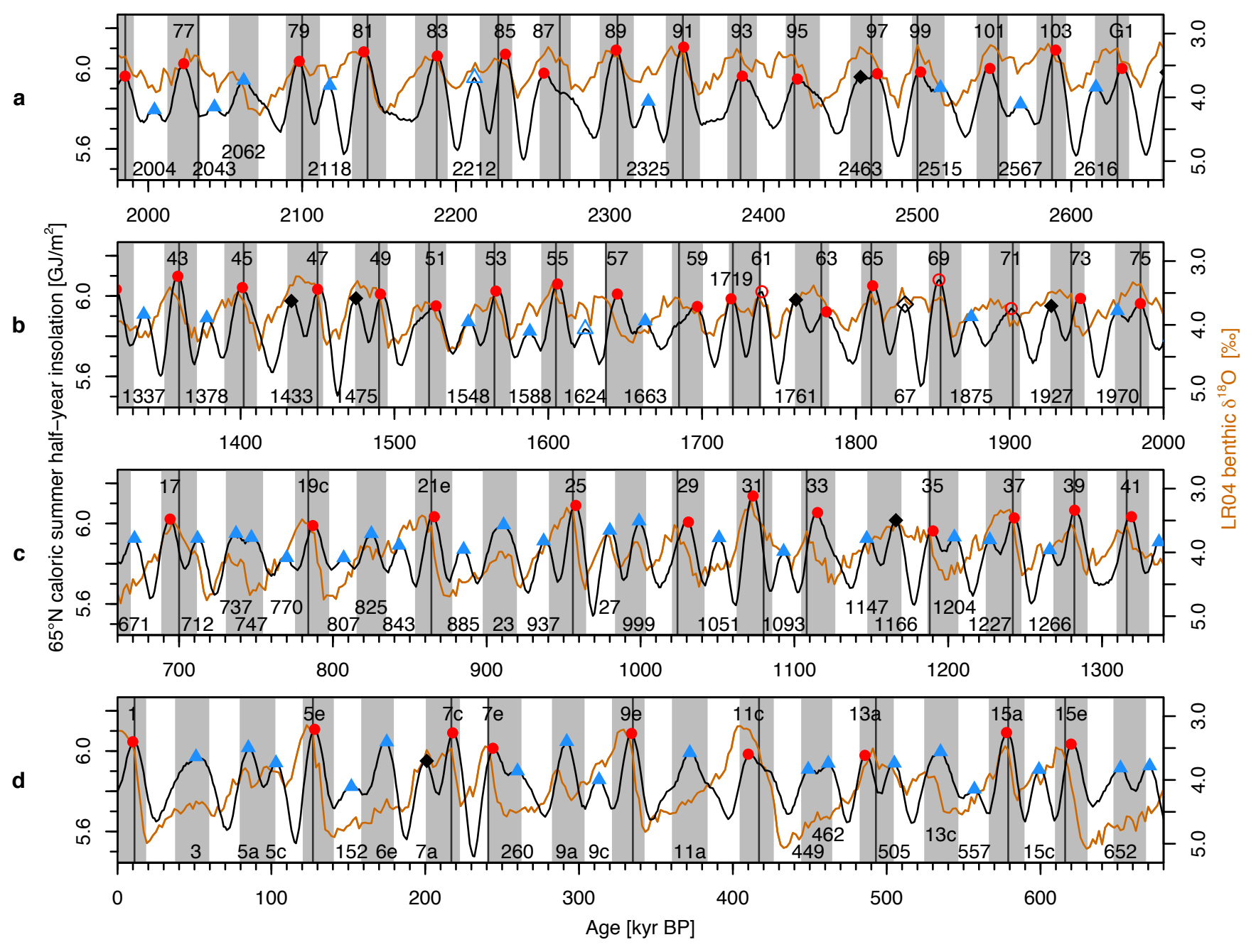

Fig. 2 


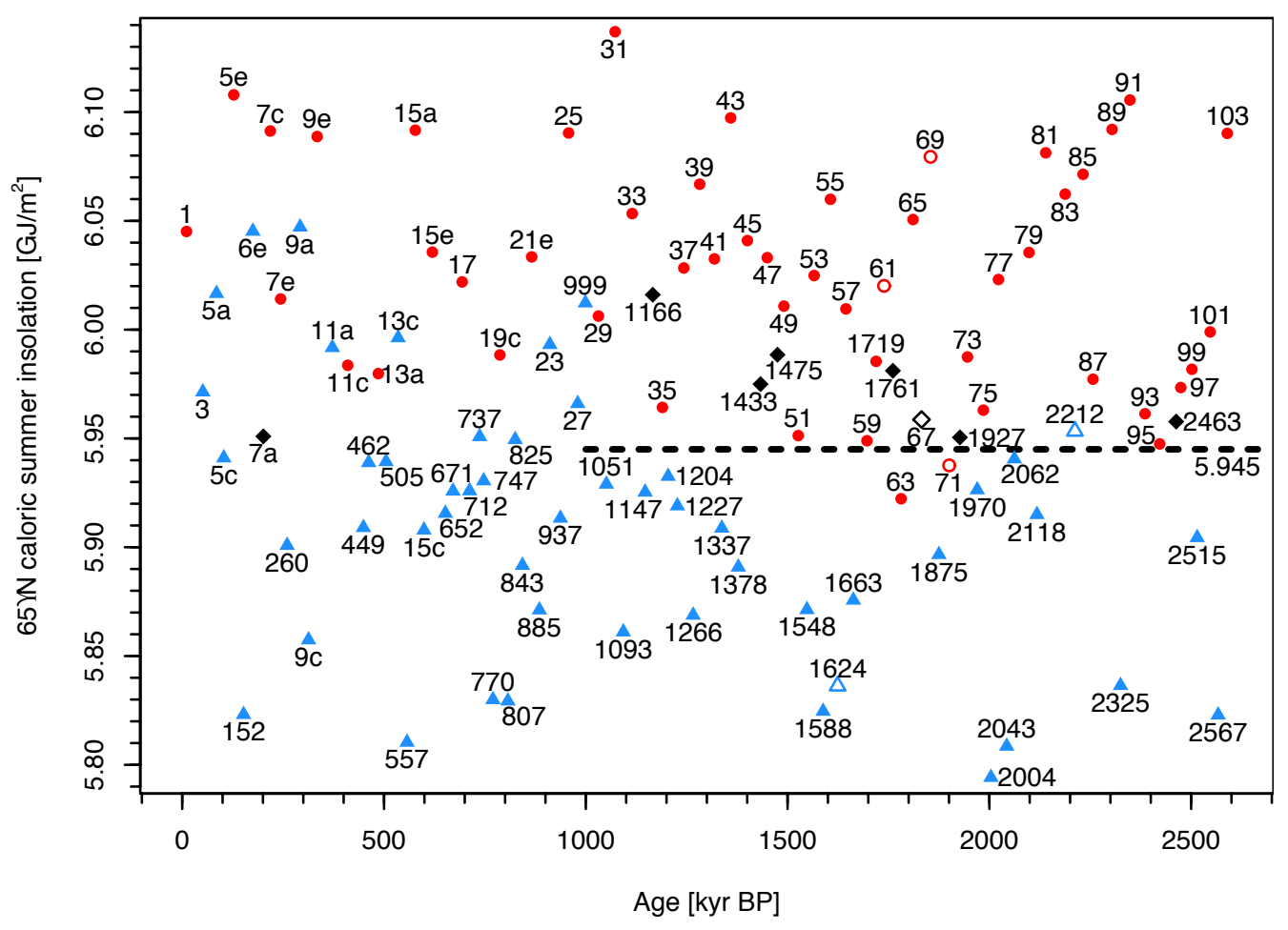

Fig. 3 


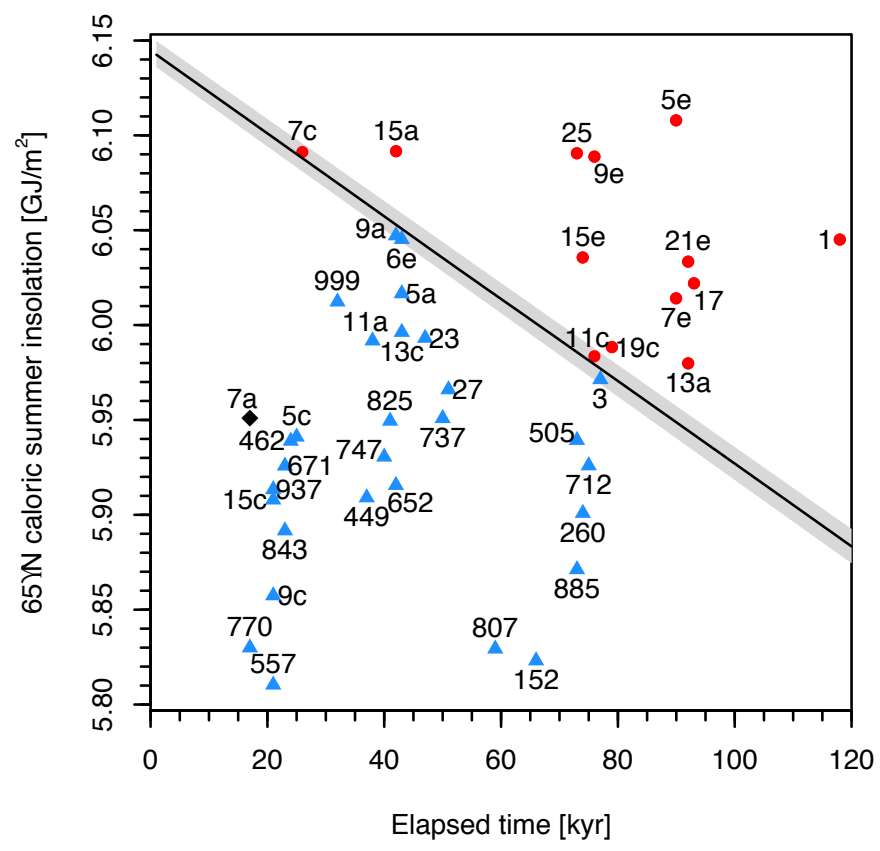

Fig. 4 


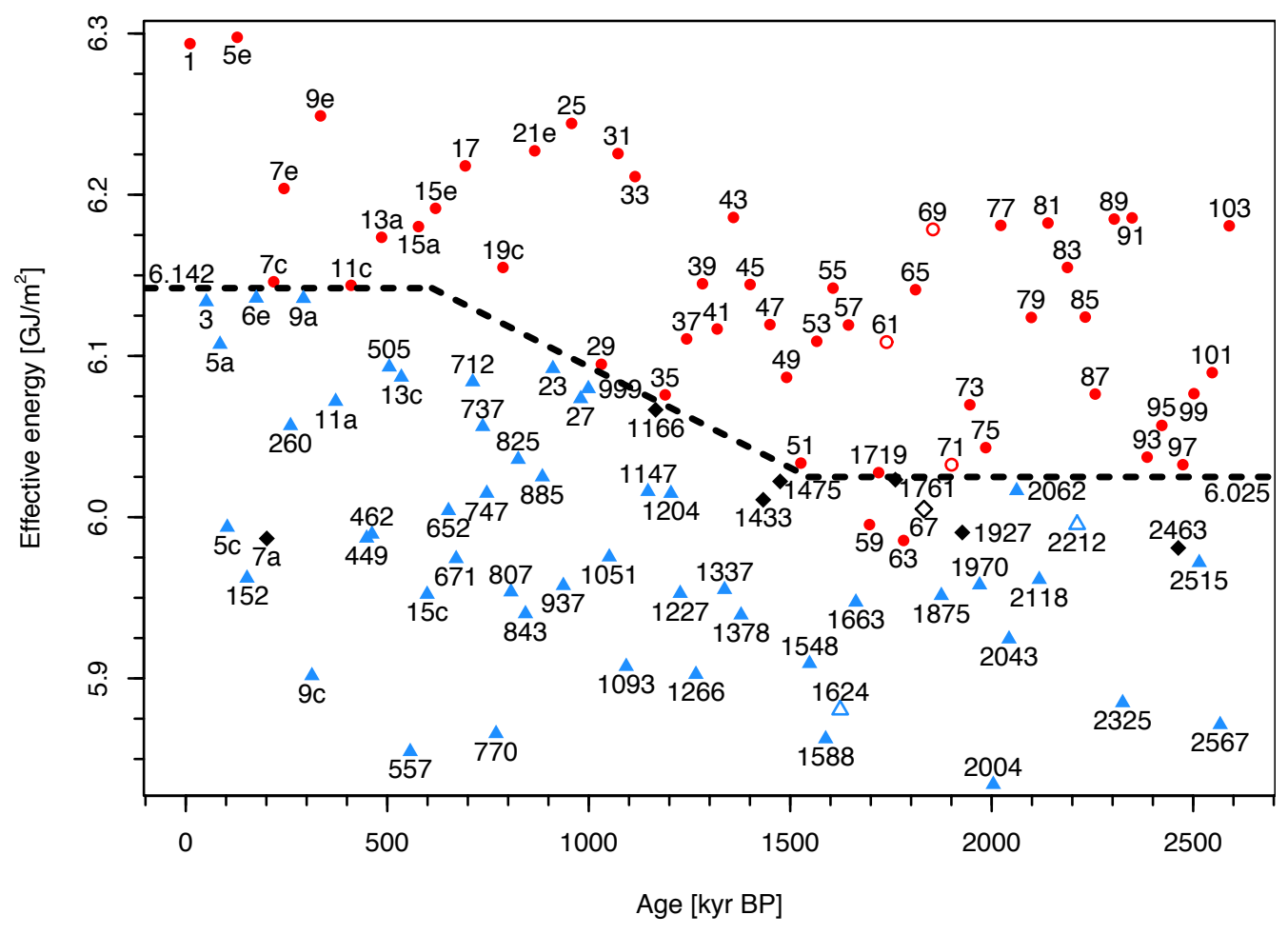

Fig. 5 

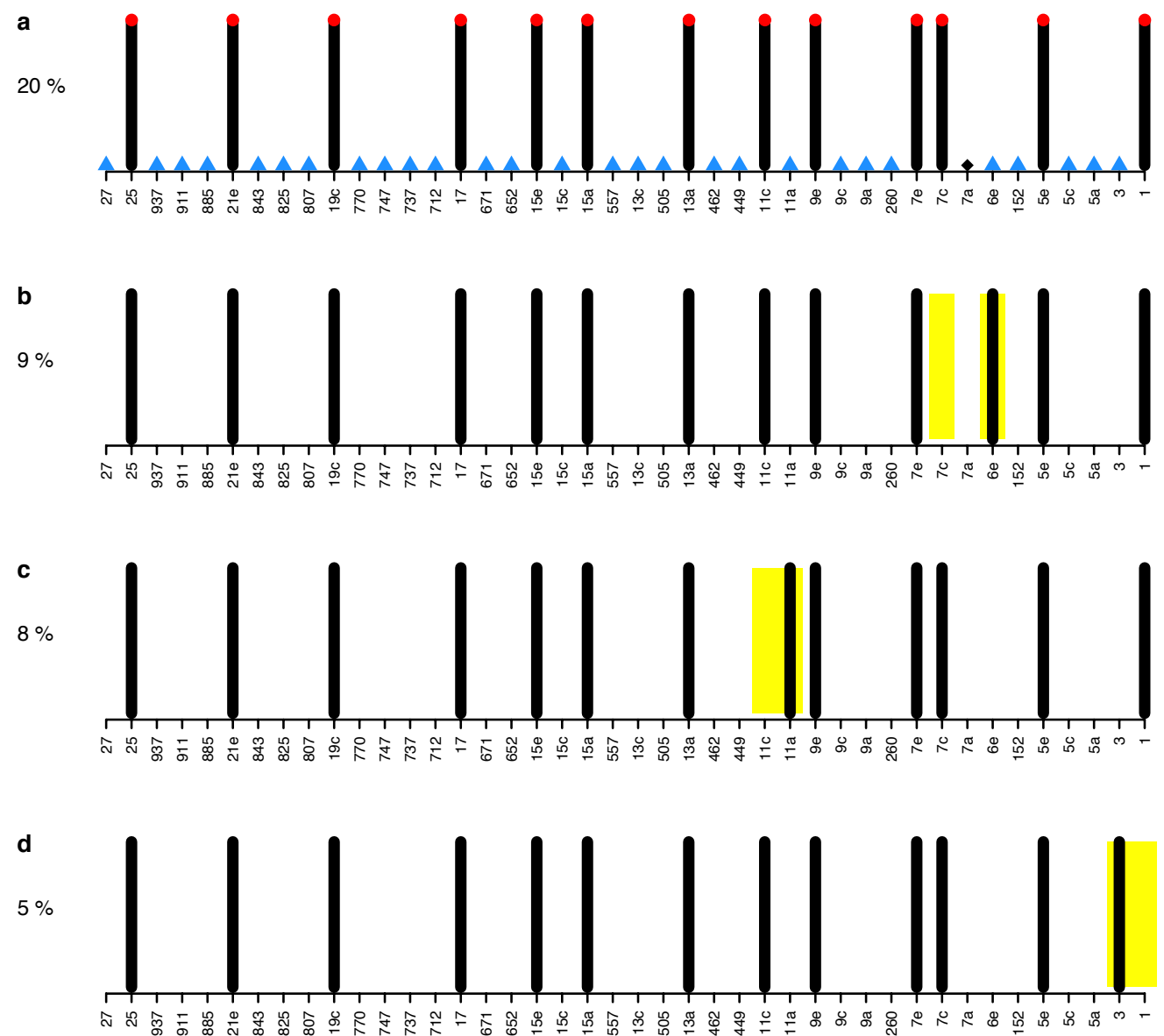

Fig. 6 

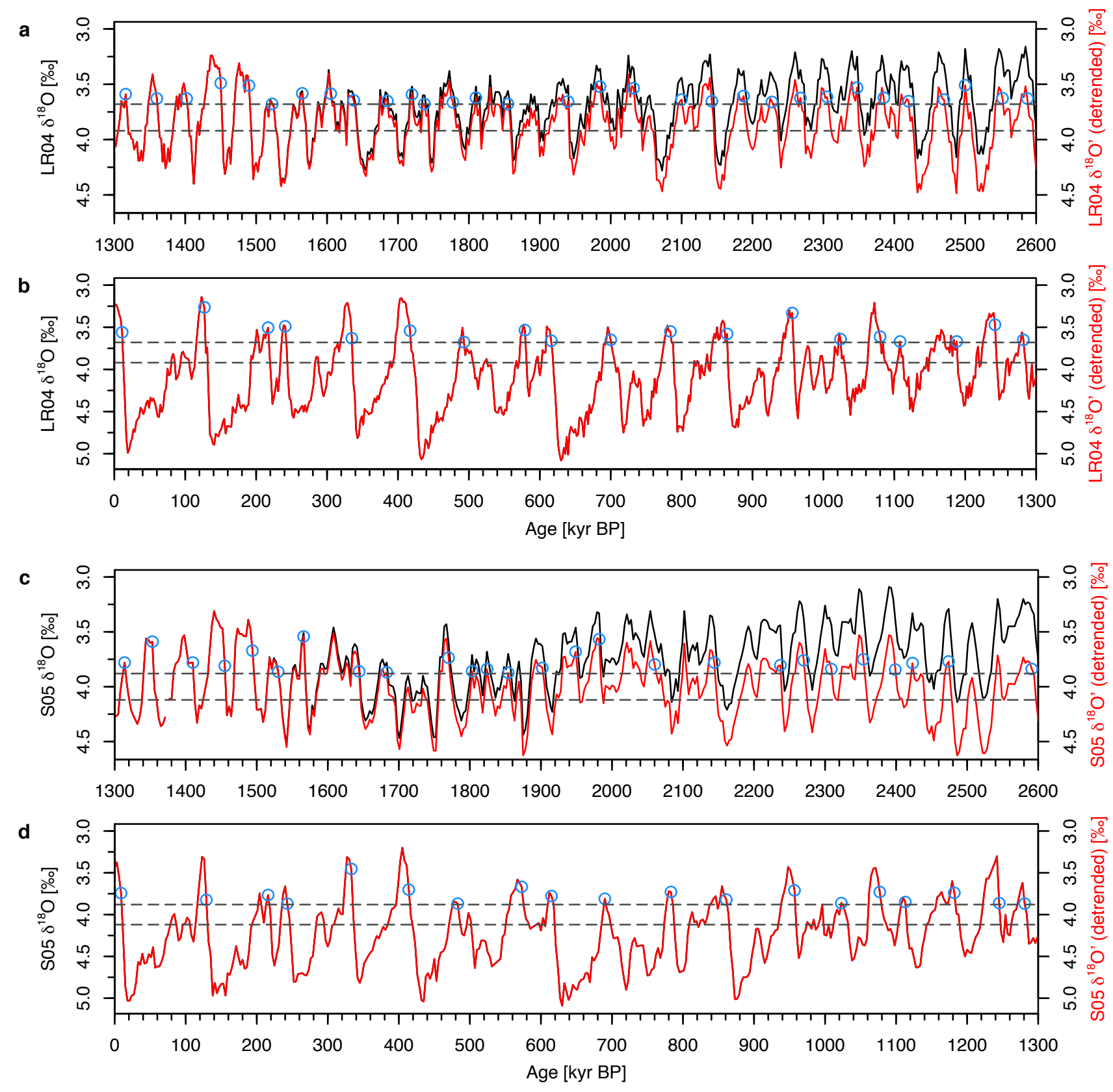

Extended Data Fig. 1 

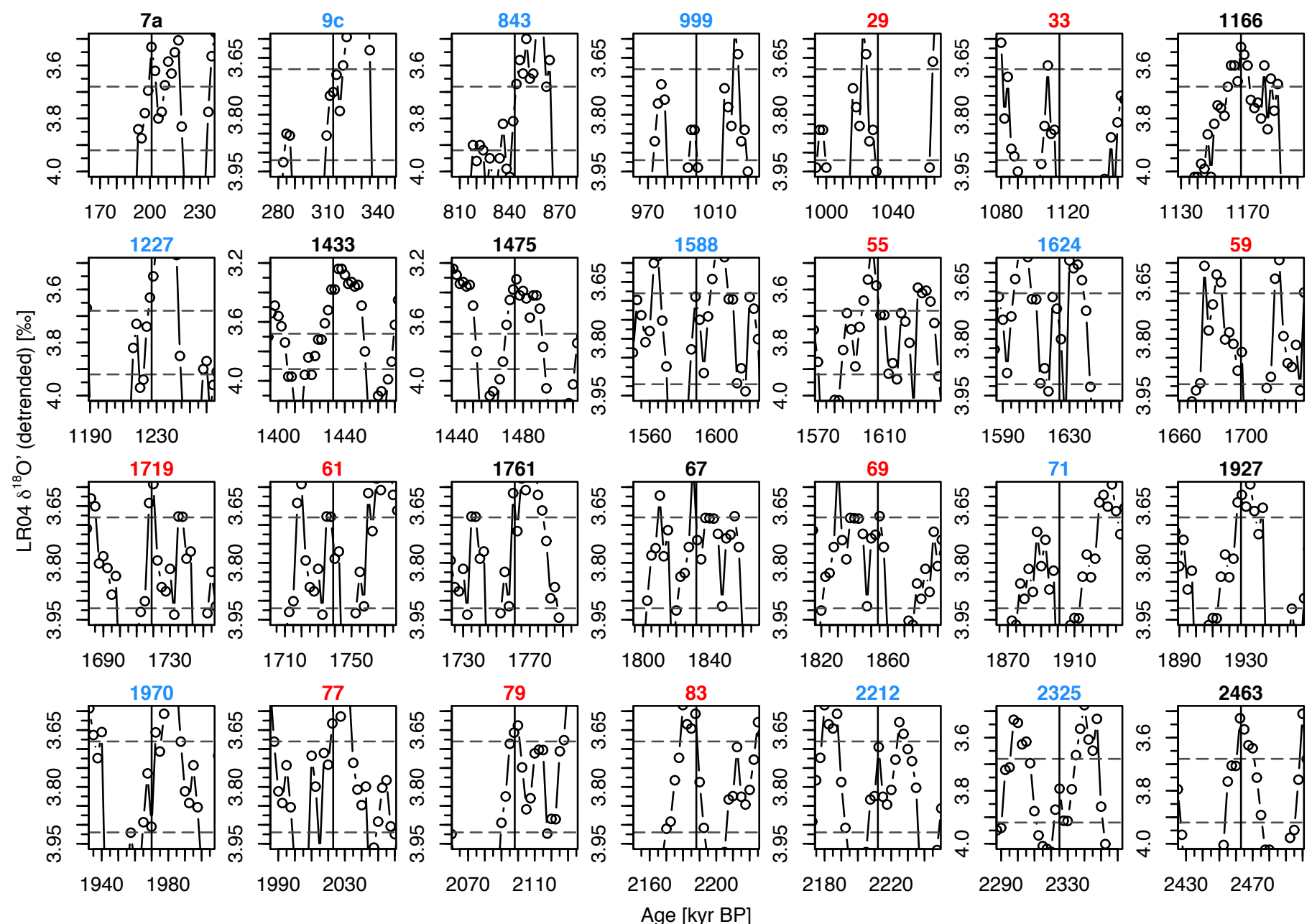

18701910

18901930

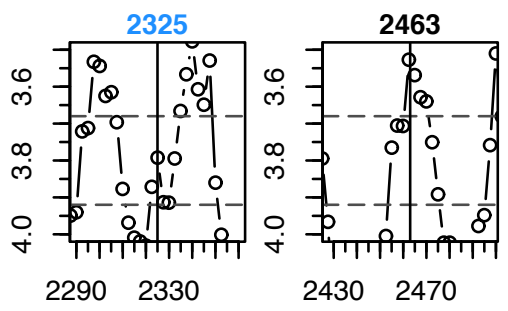

Extended Data Fig. 2 

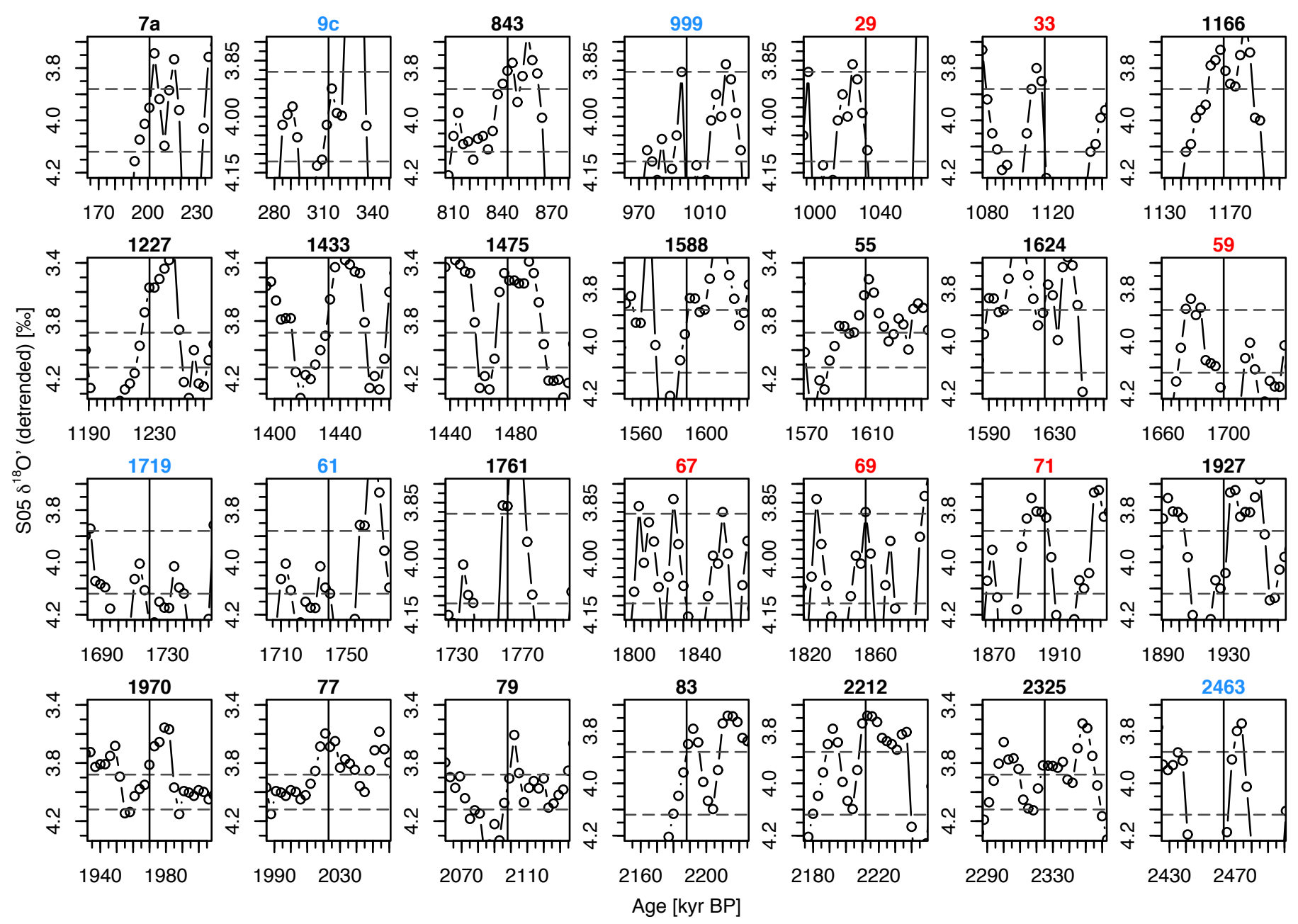


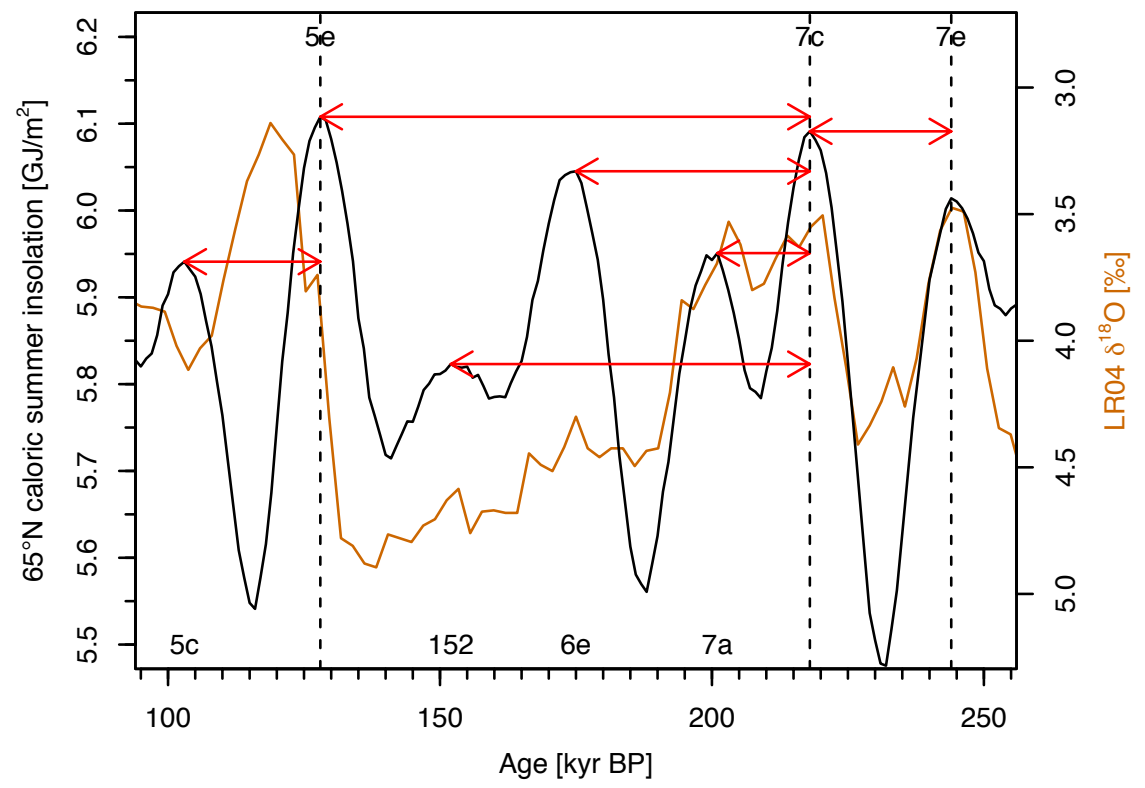

Extended Data Fig. 4 

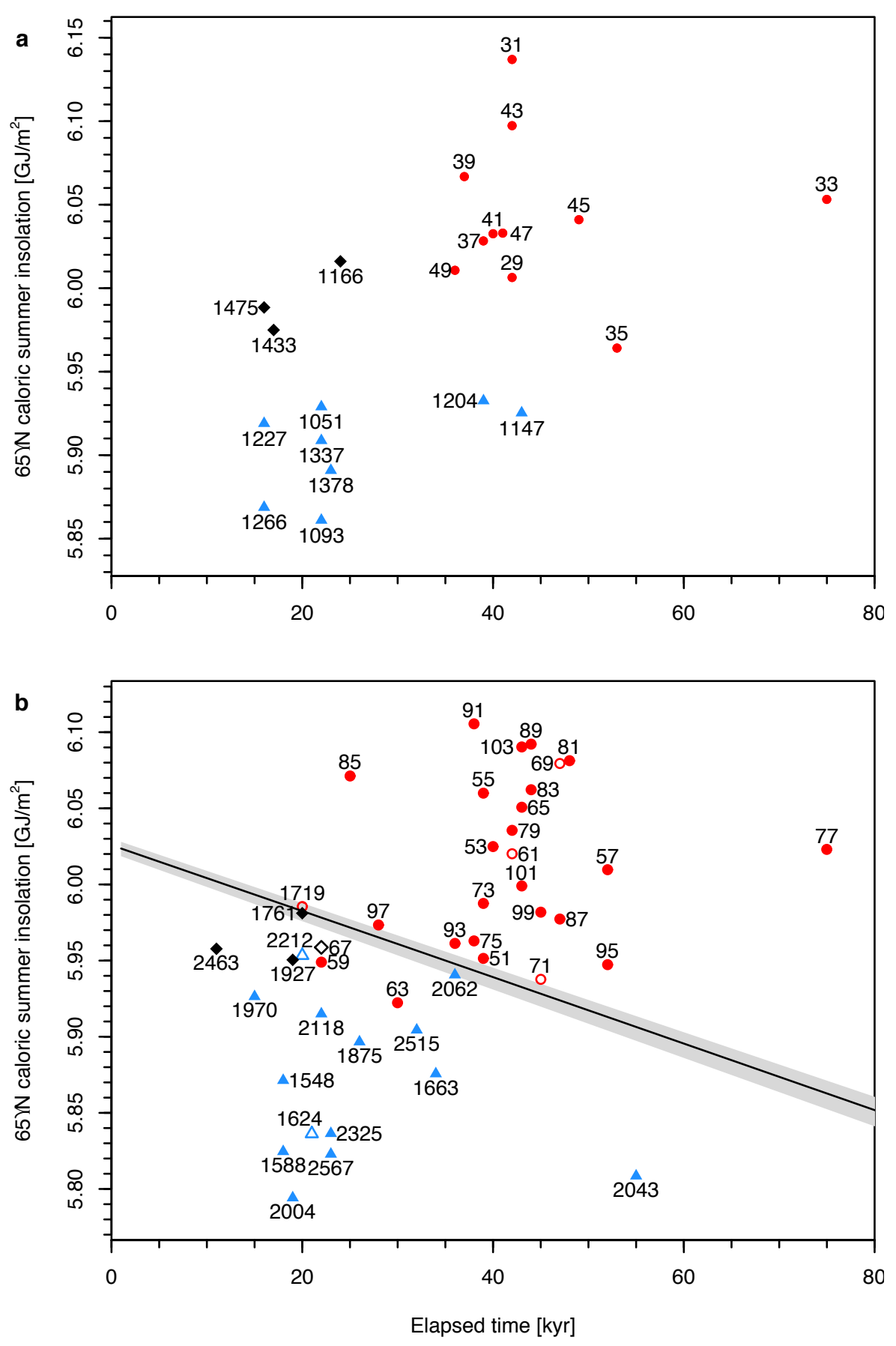

Extended Data Fig. 5 


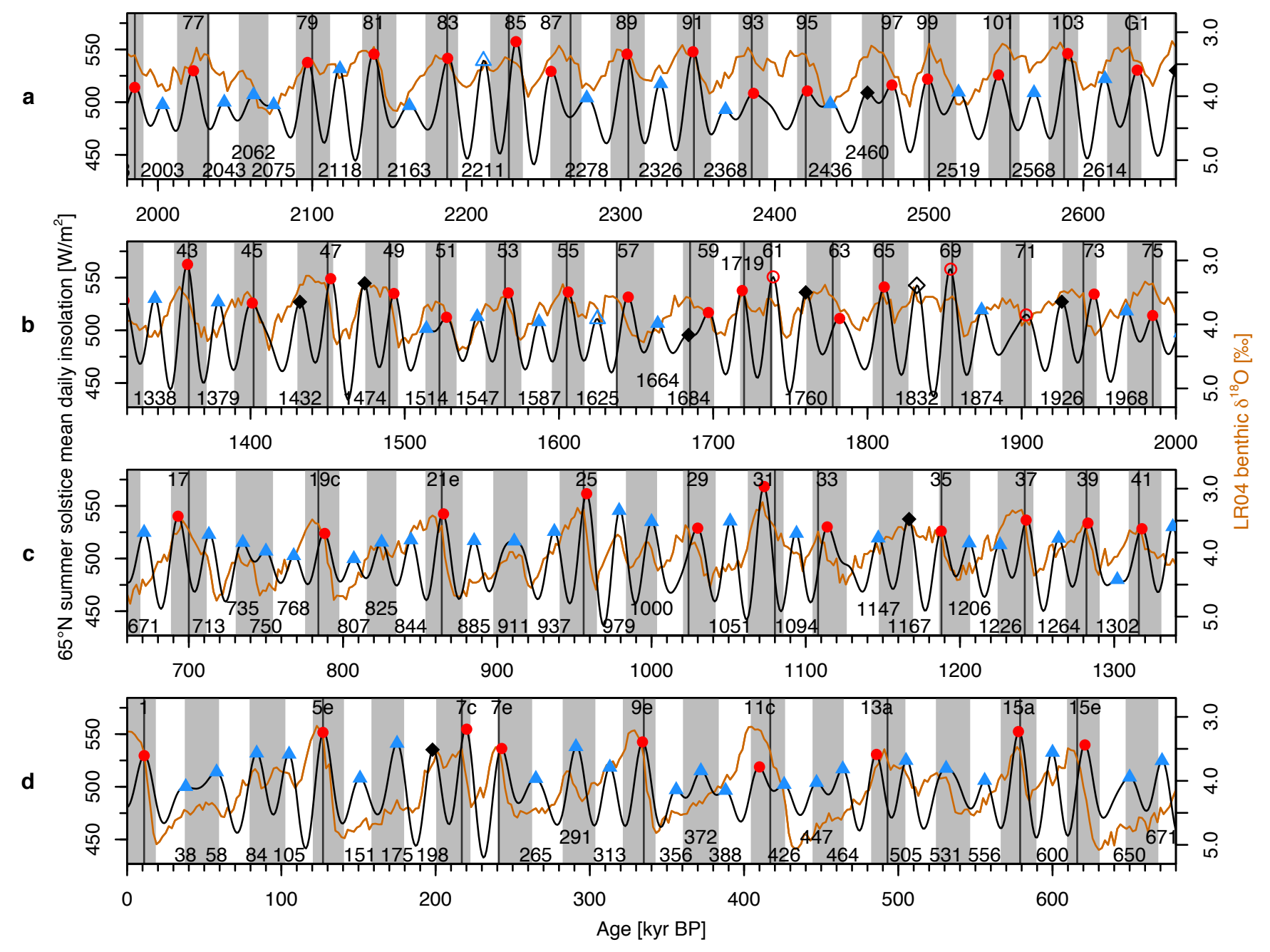

Extended Data Fig. 6 


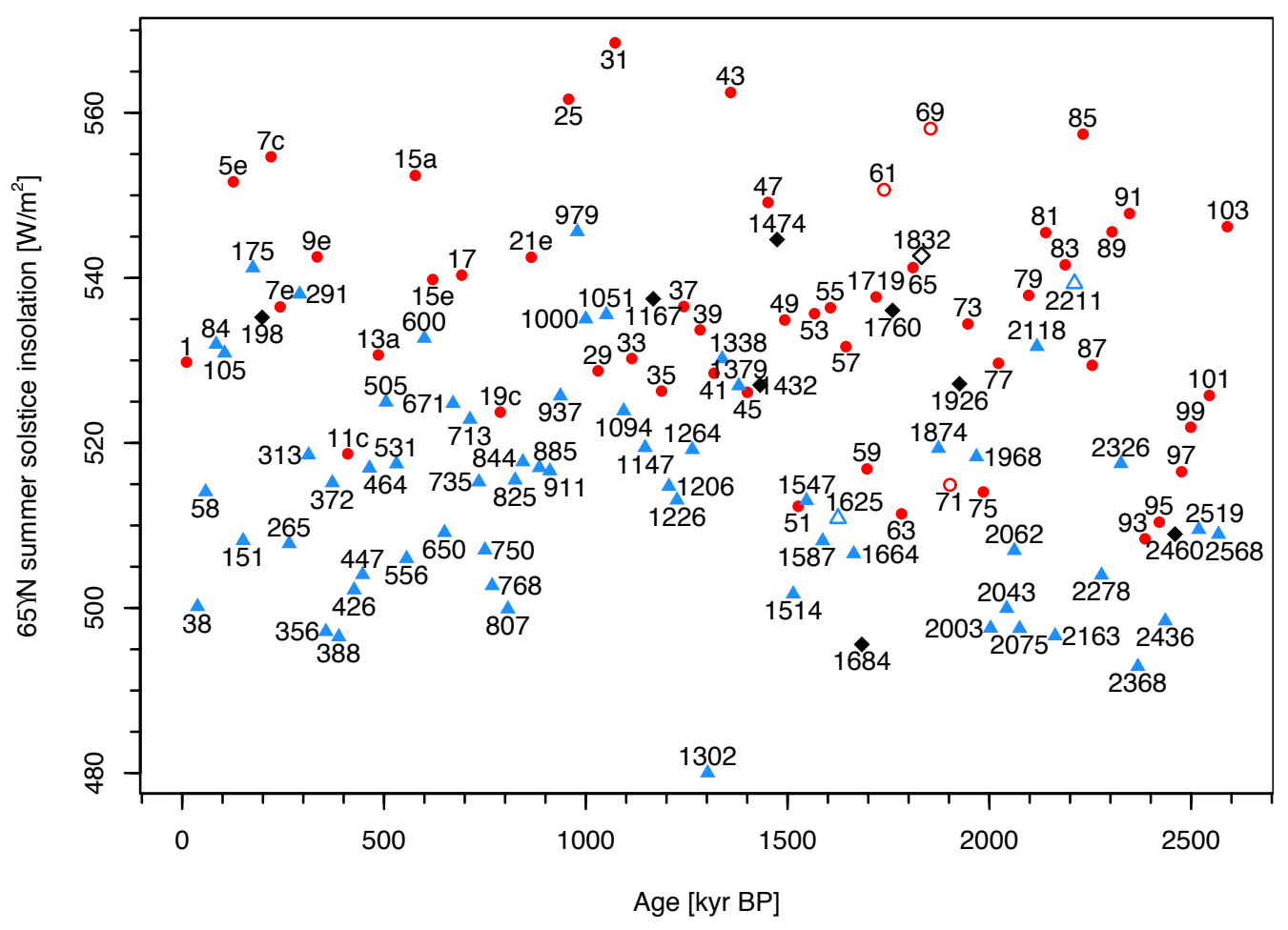

Extended Data Fig. 7 

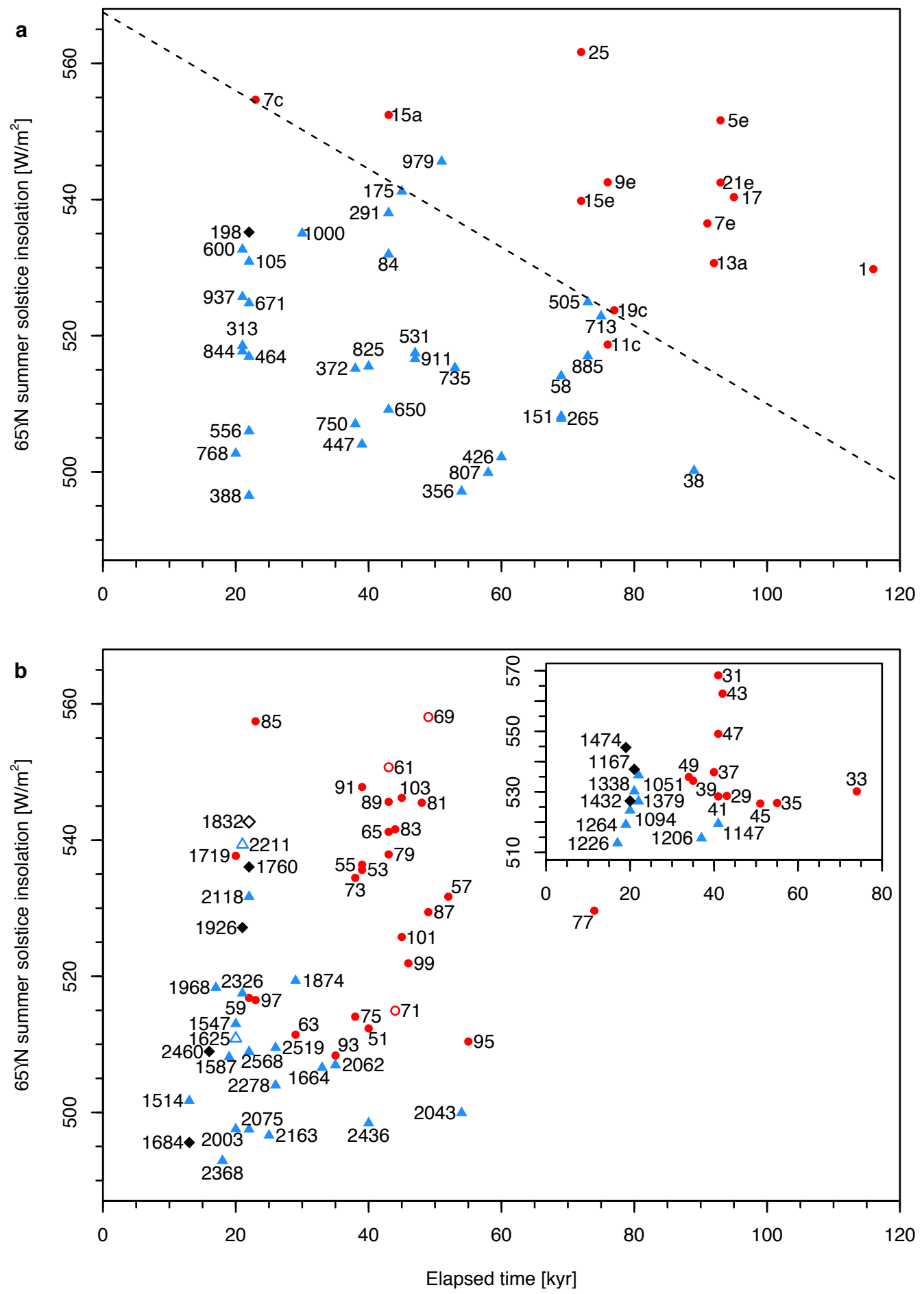

Extended Data Fig. 8 


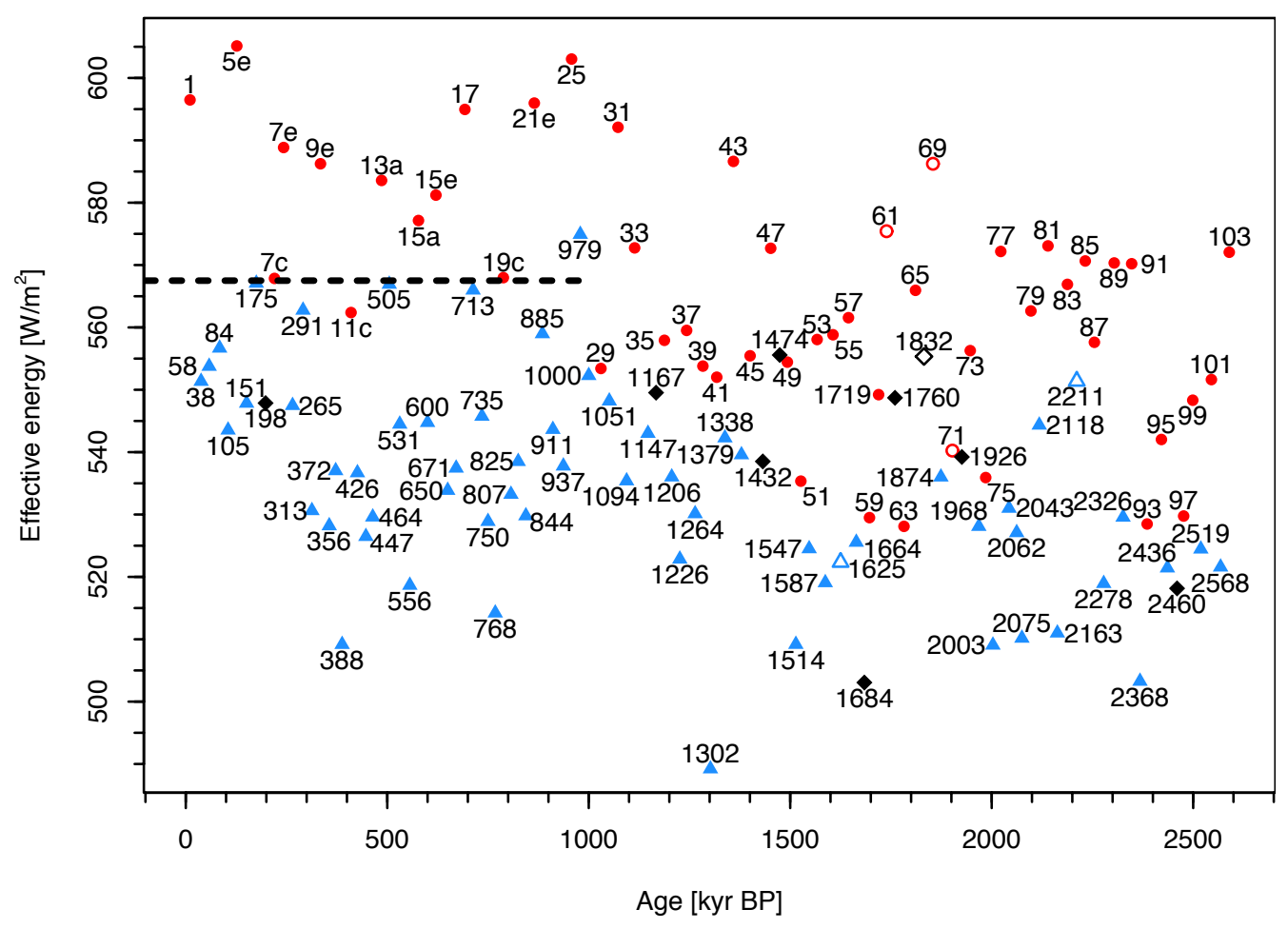

Extended Data Fig. 9 


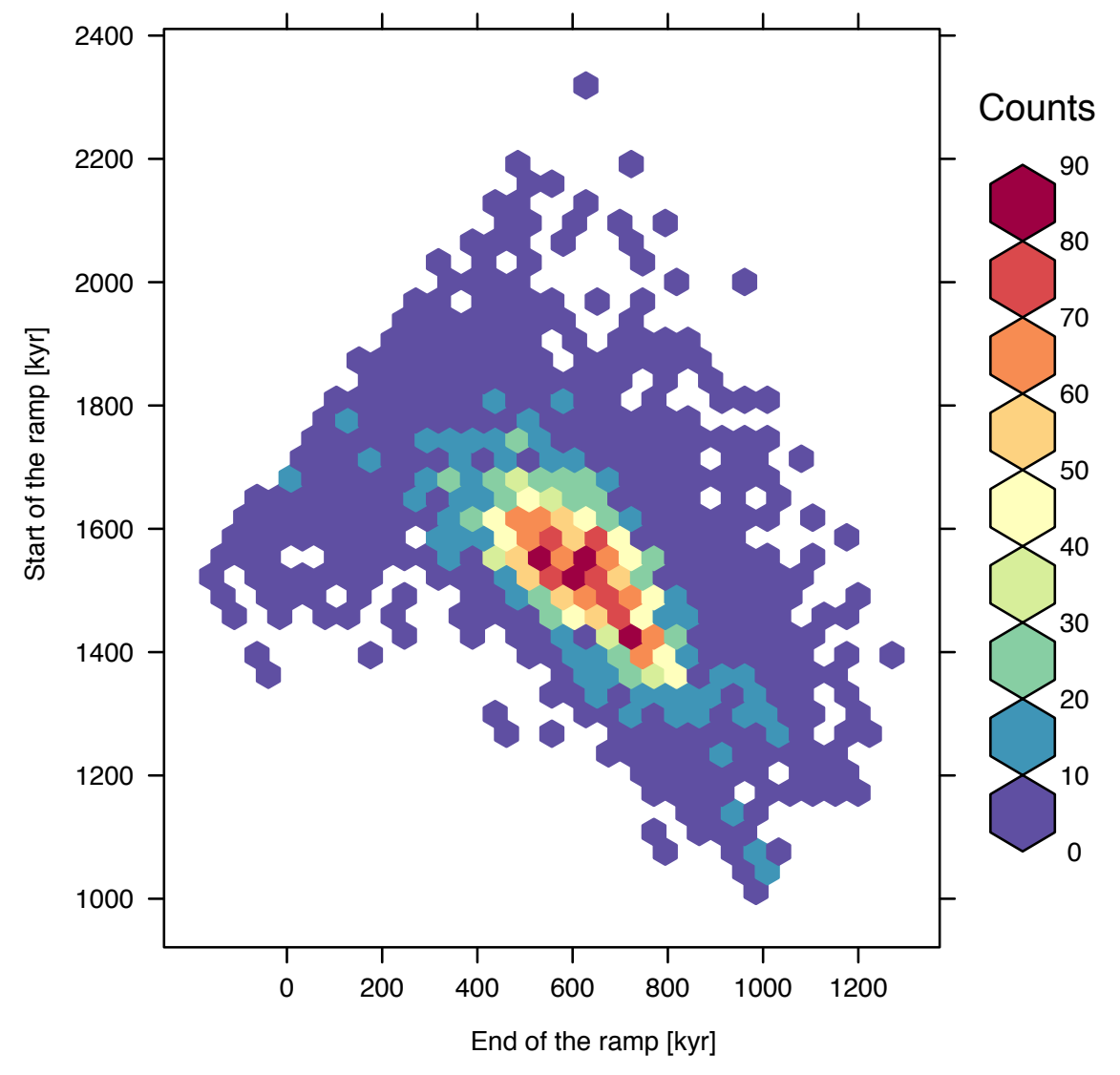

Extended Data Fig. 10 